\title{
How Well Does “Core” Inflation Capture Permanent Price Changes?
}

\author{
Michael D. Bradley \\ Department of Economics \\ George Washington University \\ mdbrad@gwu.edu \\ (202) 994-8089
}

\author{
Tara M. Sinclair ${ }^{1}$ \\ Department of Economics \\ Elliott School of International Affairs \\ George Washington University \\ tsinc@gwu.edu \\ (202) 994-7988
}

JEL Codes: C32, E31

Keywords: Consumer Price Index, Inflation, Unobserved Components, Food and Energy Prices

April 23, 2013

\begin{abstract}
Does excluding food and energy prices from the Consumer Price Index (CPI) produce a measure that captures permanent price changes? To examine this question we decompose CPI inflation and "core" inflation into their permanent and transitory components using a correlated unobserved components model. One of the key aspects of the correlated unobserved components model is that it allows shocks to the permanent component to potentially be more variable than shocks to the series itself, due to offsetting transitory shocks correlated with the permanent shocks. The stationarity of inflation may be time-varying, so we examine the performance of the core measure of inflation for periods during which it appears that inflation is I(1) and for periods during which it appears that inflation is $\mathrm{I}(0)$. For a period in which inflation appears to be I(1), we find that core inflation and the permanent component of overall inflation are closely related, although core inflation does have some drawbacks as a measure of permanent inflation. For a period in which inflation appears to be I(0), we decompose the core and overall price levels and find that the permanent component of core CPI is much more volatile than the actual core series and that core excludes volatile permanent shocks to the overall price level.
\end{abstract}

\footnotetext{
${ }^{1}$ Corresponding author. Sinclair gratefully acknowledges the generous support of the Institute for International Economic Policy (IIEP) at the Elliott School of International Affairs. Jansen thanks the Private Enterprise Research Center at Texas A\&M University for research support. The authors thank Gabriel Lade, Sasha Frankel, Amy Guisinger, and Kavita Patel for excellent research assistance and Fred Joutz and Jun Ma for helpful comments on previous drafts. We also thank John Greenlees and Peter Zadrozny of the Bureau of Labor Statistics for discussions on the construction of the Consumer Price Index. Finally, the authors thank participants in the Western Economic Association Meetings, the Society for Nonlinear Dynamics and Econometrics Annual Meetings, the Workshop on Challenges to Inflation in an Era of Relative Price Shocks at Westfälische Wilhelms University, and the NBER-NSF Time Series Conference; and seminar participants at the Federal Reserve Bank of Kansas City, the University of Kansas, Texas A\&M, William \& Mary, Loyola University Maryland, the University of Regensburg, the University of Pennsylvania, the University of Hawaii, the Bank of Canada, the Bureau of Economic Analysis, the University of Alabama, the University of Melbourne, Victoria University Wellington and the Reserve Bank of New Zealand, Australia National University, the University of New South Wales, Monash University, the University of Queensland, the Reserve Bank of Australia, and the University of Washington Conference in Honor of Charles Nelson for comments on earlier drafts.
} 


\section{A. Introduction}

Economic agents, both in the private sector and in the public policy arena, make important economic decisions in an uncertain macroeconomic environment. Two important variables characterizing that environment are the price level and the inflation rate, both of which agents take into account when making a host of economic decisions. Moreover, agents' decision making is improved if they can decompose observed price movements into their permanent and temporary components. This can be true for either changes in the price level or changes in the inflation rate, depending upon the economic environment. ${ }^{2}$

Currently observable overall or "headline" inflation provides a noisy signal about actual price level movements. One widely used approach to decompose headline inflation, both for policy makers and private sector agents, is identification of the "core" inflation rate. ${ }^{3}$ Core inflation is constructed to identify and eliminate volatile movements from the overall measure of inflation, most commonly by excluding food and energy prices. It is important to recognize, however, that volatility and impermanence are not necessarily the same thing. It is perfectly possible for permanent movements to be volatile. This possibility has often been assumed away in empirical research. For example, the classic "trend-cycle" decomposition was based solely on the assumption that the underlying (linear) trend was smooth and the cyclical deviations were temporary. It is clear that persistence is no guarantee of low volatility, and transitory components are not needed for high volatility, as is evident even in a simple random walk, a

\footnotetext{
${ }^{2}$ For some decisions, like computing the ex-ante real rate, economic agents will use the inflation rate but for others, like choosing the basket of goods to be consumed, price levels are used. For example, agents may wish to determine if an energy price increase is permanent or transitory before making an automobile purchase.

${ }^{3}$ Evidence on the importance of a core price measures in private-sector decision making is given by its persistent and widespread discussion in the popular and business press and economics blogs. For examples, see Coy, Peter, "The Great Inflation Debate,” BusinessWeek, June 13, 2008, CBC News, "Inflation, Why Do Prices Rise and Fall?" Your Money, July 17, 2009, and Picerno, James, “In Core We Trust?” The Capital Spectator, November 29, 2005. Discussions of the use of core inflation by monetary authorities are provided by Mishkin (2007), Bodenstein, Erceg and Guerrieri, (2008) and Bullard (2011).
} 
series with no temporary component. Moreover, extensive empirical research demonstrates that permanent movements in a variable can be volatile (e.g. Beveridge and Nelson, 1981; Nelson and Plosser, 1982; Morley, Nelson, and Zivot, 2003; Sinclair, 2009, Mitra and Sinclair, 2012). Such results raise the possibility that core inflation might be smooth for reasons other than the exclusion of the presumed volatile and temporary price series. It also means that the ability of core inflation to capture permanent inflation depends upon its ability to exclude temporary volatile components while not excluding or masking permanent volatile components. It is this empirical question that we address in our paper.

A key issue in evaluating how well core inflation measures permanent price changes is the nature of the stochastic process for headline inflation. If inflation is I(1), then agents face making economic decisions in an environment in which inflation experiences permanent changes. In this environment, agents will likely focus on identifying the permanent component of inflation. However, if inflation is I(0), then the long-run inflation rate is a constant and agents likely shift their focus from identifying the permanent component of inflation to identifying the permanent component of the price level. Agents can be confident that changes in the inflation rate will dissipate but would need to know if changes in the price level are permanent or temporary.

Unfortunately, the evidence on the stationarity of inflation is quite mixed and there is no consensus as to whether it is $\mathrm{I}(0)$ or $\mathrm{I}(1)$. The results of stationarity testing depend upon the time period examined and the test performed. Our own examination of the stationarity of inflation provides mixed results. Over our entire sample, the preponderance of evidence suggests that inflation has a unit root, but the evidence is not unanimous. In contrast, for significant sub- 
periods, particularly during the latter part of our sample, the evidence suggests that inflation is stationary, although again with some mixed results.

For this reason, we examine the performance of the core measure of inflation for periods during which it appears that inflation is I(1) and for periods during which it appears that inflation is $\mathrm{I}(0)$. We investigate the features of core and headline inflation, paying particular attention to the permanent and transitory components of the inflation rates constructed from these series. We decompose each inflation series into permanent and transitory components, using a multivariate extension of the correlated unobserved components model developed by Morley, Nelson and Zivot (2003). This model allows the permanent and transitory components to be correlated both within and across the series. One of the key aspects of the correlated unobserved components model is that it is possible that shocks to the permanent component may be more variable than shocks to the series itself, due to offsetting transitory shocks correlated with the permanent shocks. For a period in which inflation appears to be I(1), we find that core inflation and the permanent component of headline inflation are closely related, although we do find that the permanent component of core inflation is more volatile than core inflation itself. In addition, core inflation does have some drawbacks as a measure of permanent inflation. For example, the evidence suggests that it may overstate the permanent component of headline inflation during periods of relatively high inflation, and understate the permanent component of headline inflation during periods of relatively low inflation.

In contrast, for a period in which inflation appears to be $\mathrm{I}(0)$, we find results that raise serious concerns about the performance of the core CPI. We find that the permanent component of core is much more volatile than the actual core series. We also find that actual core CPI is smooth because it excludes the volatile permanent shocks to the headline price level, not because 
it excludes volatile temporary movements. Actual core is also smooth because its own permanent shocks are correlated with offsetting transitory shocks.

In the next section of the paper we present the unobserved components model and discuss its structure. This is followed by the data, estimation results, and interpretation of those results.

\section{B. A Multivariate Unobserved Components Model}

As mentioned above, we investigate the characteristics of core inflation to see how well it serves as a measure of permanent inflation. We do this by comparing the properties of core inflation to the properties of the permanent component of headline inflation. One factor that makes such an investigation a challenge is the fact that the permanent component of inflation is not observable. The observed inflation rate includes both permanent movements and transitory movements. A mechanism to identify these unobserved components is required.

We use an unobserved components (UC) model to investigate movements in both core and headline inflation. An unobserved components model starts by dividing an observable variable $\left(\mathrm{x}_{\mathrm{it}}\right)$ into its unobservable permanent $\left(\tau_{i t}\right)$ and transitory components $\left(c_{i t}\right)$. A bivariate version of the model is presented below, where $\mathrm{x}_{1 \mathrm{t}}$ and $\mathrm{x}_{2 \mathrm{t}}$ represent two different time series. For example, during our entire sample period when inflation is $\mathrm{I}(1), \mathrm{x}_{1 \mathrm{t}}$ represents the core inflation rate and $\mathrm{x}_{2 \mathrm{t}}$ represents the headline inflation rate. ${ }^{4}$ The structure of the model is illustrated with the observation equation:

$$
\left[\begin{array}{l}
x_{1 t} \\
x_{2 t}
\end{array}\right]=\left[\begin{array}{llllll}
1 & 0 & 1 & 0 & 0 & 0 \\
0 & 1 & 0 & 1 & 0 & 0
\end{array}\right]\left[\begin{array}{c}
\tau_{1 t} \\
\tau_{2 t} \\
c_{1 t} \\
c_{2 t} \\
c_{1 t-1} \\
c_{2 t-1}
\end{array}\right]
$$

\footnotetext{
${ }^{4}$ When we consider a subsample when inflation is $\mathrm{I}(0), \mathrm{x}_{1 \mathrm{t}}$ will represent core CPI and $\mathrm{x}_{2 \mathrm{t}}$ will represent headline CPI.
} 
The stochastic trend component, $\tau_{i t}$, is a random walk with drift, and the transitory component is modeled as a stationary AR(2) process: ${ }^{5}$ The specification of these components is contained with the state equation:

$$
\left[\begin{array}{c}
\tau_{1 t} \\
\tau_{2 t} \\
c_{1 t} \\
c_{2 t} \\
c_{1 t-1} \\
c_{2 t-1}
\end{array}\right]=\left[\begin{array}{c}
\mu_{1} \\
\mu_{2} \\
0 \\
0 \\
0 \\
0
\end{array}\right]+\left[\begin{array}{cccccc}
1 & 0 & 0 & 0 & 0 & 0 \\
0 & 1 & 0 & 0 & 0 & 0 \\
0 & 0 & \phi_{11} & 0 & \phi_{21} & 0 \\
0 & 0 & 0 & \phi_{12} & 0 & \phi_{22} \\
0 & 0 & 1 & 0 & 0 & 0 \\
0 & 0 & 0 & 1 & 0 & 0
\end{array}\right]\left[\begin{array}{c}
\tau_{1 t-1} \\
\tau_{2 t-1} \\
c_{1 t-1} \\
c_{2 t-1} \\
c_{1 t-2} \\
c_{2 t-2}
\end{array}\right]+\left[\begin{array}{cccc}
1 & 0 & 0 & 0 \\
0 & 1 & 0 & 0 \\
0 & 0 & 1 & 0 \\
0 & 0 & 0 & 1 \\
0 & 0 & 0 & 0 \\
0 & 0 & 0 & 0
\end{array}\right]\left[\begin{array}{c}
\eta_{1 t} \\
\eta_{2 t} \\
\varepsilon_{1 t} \\
\varepsilon_{2 t}
\end{array}\right]
$$

Finally, the model not only permits estimation of the permanent and transitory portions of each variable but also permits correlation between the innovations in the two components, following Sinclair's (2009) multivariate extension of Morley, Nelson, and Zivot (2003). The variance-covariance matrix is thus:

$$
E\left(\left[\begin{array}{l}
\eta_{1 t} \\
\eta_{2 t} \\
\varepsilon_{1 t} \\
\varepsilon_{2 t}
\end{array}\right]\left[\begin{array}{llll}
\eta_{1 t} & \eta_{2 t} & \varepsilon_{1 t} & \varepsilon_{2 t}
\end{array}\right]\right)=\left[\begin{array}{cccc}
\sigma_{\eta_{1}}^{2} & \sigma_{\eta_{1} \eta_{2}} & \sigma_{\eta_{1} \varepsilon_{1}} & \sigma_{\eta_{1} \varepsilon_{2}} \\
\sigma_{\eta_{1} \eta_{2}} & \sigma_{\eta_{2}}^{2} & \sigma_{\eta_{2} \varepsilon_{1}} & \sigma_{\eta_{2} \varepsilon_{2}} \\
\sigma_{\eta_{1} \varepsilon_{1}} & \sigma_{\eta_{2} \varepsilon_{1}} & \sigma_{\varepsilon_{1}}^{2} & \sigma_{\varepsilon_{1} \varepsilon_{2}} \\
\sigma_{\eta_{1} \varepsilon_{2}} & \sigma_{\eta_{2} \varepsilon_{2}} & \sigma_{\varepsilon_{1} \varepsilon_{2}} & \sigma_{\varepsilon_{2}}^{2}
\end{array}\right]
$$

Estimation of the model includes estimation of correlations among the permanent and transitory innovations in both variables where we assume the innovations are jointly normally distributed. We apply the Kalman filter for maximum likelihood estimation (MLE) of the

\footnotetext{
${ }^{5}$ At least AR(2) dynamics are necessary for identification (see discussion in Morley, Nelson and Zivot, 2003, and Sinclair, 2009). Additional lags did not change the key results; therefore we selected the most parsimonious model. An additional benefit of the AR(2) specification is that it makes it much easier to ensure the global maximum using the constraint described in Morley (1999).
} 
parameters using prediction error decomposition and to estimate the permanent and transitory components.

\section{The Data}

We estimate the unobserved components model for monthly US CPI data (consumer price index for all urban consumers). We estimate a series of bivariate models involving three different series (all seasonally adjusted): 1) Headline CPI, 2) All Items Less Food and Energy (or Core) CPI, and 3) A Combined Food and Energy CPI. The sample starts in January of 1983 and ends in December of 2012. Our data begin in 1983 for two reasons. First we avoid the definitional change regarding shelter in the CPI. Before 1983, mortgage interest rates which were included in the CPI as a part of homeowner’s costs, whereas since 1983 a rental equivalence measure has been used (see Smith, 2005). Second, the 1983 start date also allows us to avoid issues of different monetary policy regimes as discussed in Murray, NikolskoRzhevskyy, and Papell (2008). ${ }^{6}$ Finally, because we calculate inflation as the year-over-year change in the price index, the actual estimation period begins in 1984.

Figure 1 presents the inflation rates for the core and headline series (measured as the log difference of the year-over-year values for the index). This plot of the inflation rates immediately reveals the appeal of core inflation as a measure of "long-run” inflation. Core inflation is much smoother than headline inflation because it excludes the variation that is present in food and energy inflation. However, this simple comparison potentially overstates the case for the use of core inflation because it fails to focus on the true permanent or "long-run" component of inflation.

\footnotetext{
${ }^{6}$ This difference was also discussed in much earlier work by Bradley and Jansen (1986) among others.
} 
One straightforward method of beginning the examination of the permanent inflation is to estimate univariate unobserved components models for the inflation series. These univariate models are likely misspecified because they do not allow for possible cross-series correlations, but they do provide a useful preliminary method for investigating the permanent behavior of inflation.

For example, Figure 2 presents the univariate permanent component of headline inflation along with the actual series. This shows that the permanent component of headline inflation is much smoother than the actual series and indicates that a closer look at the relationship between core inflation and permanent inflation is required. This point is reinforced by Figure 3 which compares core inflation with the estimated permanent component of headline inflation. This figure shows that core inflation is materially more variable than the permanent component of headline inflation in the univariate model, calling into question the utility of core inflation as a measure of the permanent component or long run trend in headline inflation. Stated differently, while core inflation may appear smooth relative to overall headline inflation, it does not appear smooth relative to the permanent part of headline inflation. As a result, estimation of appropriate empirical models is required to make a determination about how well core inflation captures permanent price changes.

\section{Testing For Stationarity and Cointegration of Inflation Rates}

Before going further, it is important to determine whether the model should be estimated for the inflation rates or (log) price levels. The unobserved components model specifies a random walk for the permanent component, so it is not appropriate for a stationary series. If the inflation processes are I(1), then it is appropriate to construct an unobserved components model 
for inflation rates. ${ }^{7}$ On the other hand if the inflation processes are $\mathrm{I}(0)$, then the unobserved components model should be constructed for price levels which themselves are I(1).

Moreover, if the inflation processes are I(1), then a determination must be made whether or not the included inflation rates are cointegrated (Kiley, 2008). If they are, then a common trend unobserved components model could result in more efficient estimation of the model parameters and the common trend. If they are not cointegrated, then an unrestricted unobserved components model should be used which allows for different long-run trends in the included inflation rates. Because of the importance of this specification choice for determining results, we carefully consider the various possibilities.

There is debate about whether or not US inflation is stationary. For example, Pivetta and Reis (2007) find that data from 1965 to 2001 do not reject a unit root in inflation and argue that inflation persistence has remained high and relatively unchanged over their sample. Similarly, Stock and Watson (2007) find a unit root in inflation for both 1970-1983 and 1984-2004. On the other hand, Leybourne, Kim, Smith, and Newbold (2003) and Murray, Nikolsko-Rzhevskyy, and Papell (2008) find that inflation is stationary starting in the early 1980s. Kang, Kim, and Morley (2009) find that U.S. inflation persistence experience a sudden decrease in inflation persistence in the early 1980’s after experience an increase in persistence at the beginning of the 1970's. ${ }^{8}$

\footnotetext{
${ }^{7}$ Alternatively we could estimate a model for the price levels where the drift term is modeled as a random walk so that the price levels are I(2). Oh and Zivot (2006) and Creal, Oh, and Zivot (2008) show that a correlated version of this "double-drift" model is not identified without additional restrictions. We therefore focus on directly modeling inflation with an unobserved components model in the case where prices are I(2)

${ }^{8}$ Piger and Rasche (2008) also find that "the size of permanent shocks to the inflation rate has varied substantially over the sample period." They find for the end of their sample, from 1994-2005, that the permanent shocks to inflation are "quite small from a historical perspective" (page 101).
} 
We follow this literature by testing for stationarity. We employ a battery of stationarity tests including the KPSS test, the augmented Dickey Fuller test, the Phillips-Peron test, and the MPS test put forward by Morley et al (2012). ${ }^{9}$

The results are presented in Table 1. We find mixed evidence on the stationarity of inflation. For the 1984 - 2012 period, the KPSS tests indicates that both core inflation and headline inflation are stationary as in neither case does the test statistic indicate a rejection of the null hypothesis of stationarity. The MPS test statistics, in contrast, indicate rejection of stationarity for both series. Finally, both the ADF and Phillips-Peron tests indicate that headline inflation is stationary while core inflation is non-stationary. In sum, one of the four tests indicates that headline inflation is non-stationary but three of the four tests indicate that core inflation is non-stationary.

We also look at these inflation rates over a more recent period, 1993 - 2012. This period was chosen because structural break tests on core CPI indicate a break in 1993.03. In this more recent period, the KPSS and MPS tests support an inference that both headline and core inflation are stationary. The ADF and Phillips-Peron tests produce more mixed evidence with the ADF indicating that both inflation series are non-stationary and the Phillips-Peron test indicating that headline inflation is stationary and core inflation is not.

These results lead us to investigate two approaches to modeling inflation with our correlated unobserved components model. We model inflation for the full period, when the tests indicate it is I(1). We model (log) price levels for the important sub-period for which tests indicate inflation is $\mathrm{I}(0)$.

\footnotetext{
${ }^{9}$ The MPS tests the null hypothesis of stationarity, similar to the KPSS test, but with better properties when dealing with data generating processes of the kind relevant for correlated unobserved component models.
} 
For the period in which both headline inflation and core inflation appear to be I(1), we test if the two series are cointegrated. The Johansen test indicates that they have one cointegrating vector. This raises the possibility that we could estimate a restricted unobserved components model in which we impose a single long-run component on the two inflation measures. However, because of the mixed results on stationarity and because of the importance of such a restriction to the interpretation of the results, we estimate the unobserved components model for inflation two ways. First, we estimate an unrestricted unobserved components model to see if the results support a common long-run component between headline and core inflation. If the two series truly are cointegrated, then an unrestricted model should produce a similar longrun component for both series. Second, we estimate a restricted unobserved components model with the assumption of a common long-run component in place.

\section{E. Model Estimation}

As explained in the previous section, we estimate three unobserved components models, two for inflation rates and one for the level of prices. We take this approach to provide a broad set of results on the performance of the core inflation as a measure of permanent price level changes. By taking these different approaches we are ensuring that our results and conclusions are not limited by the results of empirical tests of stationarity and cointegration that are known to provide conflicting evidence.

\section{An Unrestricted Unobserved Components Model in Core and Headline Inflation}

The first bivariate model we estimate is the unrestricted unobserved components model for core inflation and headline inflation. This model allows the two inflation series to have different long-run properties, including different drifts and different sequences of permanent shocks. The resulting parameter estimates are presented in Table 2 and the estimated permanent 
components are presented in Figure 4. A key finding is that short-run shocks to core inflation are negatively correlated with its long-run shocks, with a high degree of correlation, as the estimated correlation coefficient is -0.936 . This allows for core inflation to be smoother than its permanent component, as permanent shocks are offset by temporary shocks in the other direction. At the same time, the standard deviation of permanent shocks to core inflation is larger than the standard deviation of permanent shocks to headline (CPI) inflation, 0.167 versus 0.105 . Finally, both core and headline inflation rates have negative, but statistically insignificant, drift terms over the period of estimation.

In Figure 4, the estimated permanent component of headline inflation is shown to be considerably smoother than CPI inflation. The graph of core inflation and the permanent component of core inflation suggests that core inflation may be a good proxy for the permanent component of core inflation when inflation is I(1). This is also suggested by the estimates of the standard deviation of shocks to the temporary part of core inflation, which is 0.047 as compared with to standard deviation to the permanent part of core inflation, which is 0.167 . Shocks to the temporary part of core inflation are an order of magnitude smaller than shocks to the permanent component.

Figure 5 presents the two permanent components together. The two series appear to share a fair amount of co-movement in their permanent components which lends support to the idea of using core inflation as a measure of permanent inflation. However, the permanent core inflation series appears to be more volatile than the permanent component of headline inflation, which reduces its utility. The permanent component of core inflation also may be biased relative to the permanent component of headline inflation. The apparent bias arises from the fact that permanent core inflation is persistently above permanent headline inflation during periods in 
which the average inflation rate is relatively high and is persistently below permanent headline inflation during period in which inflation is relatively low.

We can gain additional insight into the dynamics of core inflation by examining the short run component. We first note that both core inflation and headline inflation exhibit a high degree of persistence in their transitory components. The sum of the AR coefficients for the short-run core inflation model is 0.834 and the sum of the coefficients for the short-run headline inflation model is 0.888 . A good way to investigate the short run component is to calculate how core inflation would react to a one standard deviation permanent shock. Given the large negative correlation between permanent and transitory shocks to core inflation, a positive permanent shock is likely to be accompanied by a largely offsetting negative transitory shock, resulting in little initial increase in actual core inflation at the time of the shock. In subsequent periods, the short-run autoregressive model causes actual core index to temporarily move in the "wrong" direction before it begins to approach its permanent value. The short run model, illustrated in Figure 6, indicates that it takes seven to eight months before actual core inflation approaches its long run value. This is entirely consistent with the slow price adjustment or "inflation stickiness" associated with many items in the core index. ${ }^{10}$ It also is another piece of evidence that actual core inflation may be an overly smooth estimate of long-run inflation.

\section{A Restricted Unobserved Components Model in Core and Headline Inflation}

The unrestricted model identifies the permanent and transitory components of both core inflation and headline inflation for the case in which they are not cointegrated. If they are cointegrated, a restricted unobserved components model is appropriate (Morley, 2007). Given the mixed evidence on unit roots and cointegration, we also estimate this restricted unobserved components model. This model restricts the two inflation series, headline and core, to share a

\footnotetext{
${ }^{10}$ Inflation stickiness is discussed, for example, by Roberts (1997).
} 
single long-run component. The observation equation thus includes only a single stochastic trend for both inflation rates. The model does allow for a scaling parameter, $\gamma$, between the two long-run components:

$$
\left[\begin{array}{l}
\pi_{1 t} \\
\pi_{2 t}
\end{array}\right]=\left[\begin{array}{lllll}
1 & 1 & 0 & 0 & 0 \\
\gamma & 0 & 1 & 0 & 0
\end{array}\right]\left[\begin{array}{c}
\tau_{t} \\
c_{1 t} \\
c_{2 t} \\
c_{1 t-1} \\
c_{2 t-1}
\end{array}\right]
$$

With only one stochastic trend, there is just one long-run shock in the state equation:

$$
\left[\begin{array}{c}
\tau_{t} \\
c_{1 t} \\
c_{2 t} \\
c_{1 t-1} \\
c_{2 t-1}
\end{array}\right]=\left[\begin{array}{l}
\mu \\
0 \\
0 \\
0 \\
0
\end{array}\right]+\left[\begin{array}{ccccc}
1 & 0 & 0 & 0 & 0 \\
0 & \phi_{11} & 0 & \phi_{21} & 0 \\
0 & 0 & \phi_{12} & 0 & \phi_{22} \\
0 & 1 & 0 & 0 & 0 \\
0 & 0 & 1 & 0 & 0
\end{array}\right]\left[\begin{array}{c}
\tau_{t-1} \\
c_{1 t-1} \\
c_{2 t-1} \\
c_{1 t-2} \\
c_{2 t-2}
\end{array}\right]+\left[\begin{array}{ccc}
1 & 0 & 0 \\
0 & 1 & 0 \\
0 & 0 & 1 \\
0 & 0 & 0 \\
0 & 0 & 0
\end{array}\right]\left[\begin{array}{c}
\eta_{t} \\
\varepsilon_{1 t} \\
\varepsilon_{2 t}
\end{array}\right]
$$

The elimination of a second long-run shock also simplifies the variance-covariance matrix:

$$
E\left(\left[\begin{array}{l}
\eta_{1 t} \\
\varepsilon_{1 t} \\
\varepsilon_{2 t}
\end{array}\right]\left[\begin{array}{lll}
\eta_{1 t} & \varepsilon_{1 t} & \varepsilon_{2 t}
\end{array}\right]\right)=\left[\begin{array}{ccc}
\sigma_{\eta}^{2} & \sigma_{\eta_{\varepsilon_{1}}} & \sigma_{\eta_{\varepsilon_{2}}} \\
\sigma_{\eta_{\varepsilon_{1}}} & \sigma_{\varepsilon_{1}}^{2} & \sigma_{\varepsilon_{1} \varepsilon_{2}} \\
\sigma_{\eta_{\varepsilon_{2}}} & \sigma_{\varepsilon_{1} \varepsilon_{2}} & \sigma_{\varepsilon_{2}}^{2}
\end{array}\right]
$$

The estimated parameters for this restricted model are presented in Table 3 and the permanent components of the model are presented in Figure 7. If core inflation and headline inflation are cointegrated, a single permanent component represents the long-run behavior in both. In this sense, the permanent component of core is also the (possibly scaled) permanent component of headline inflation. Moreover, the actual core inflation rate appears to closely align with the common permanent component of inflation. These results are favorable to the use of core inflation as a measure of long-run inflation.

However, even in this case, actual core inflation may have drawbacks as a measure of permanent inflation. Table 3 shows that in the restricted model there is again a large negative 
correlation between permanent and transitory shocks to core inflation, -0.720 , suggesting that core inflation may be too smooth a measure of permanent inflation. In contrast, transitory shocks to headline inflation are positively correlated with permanent shocks to inflation and the transitory shocks are slightly negatively correlated across the two series.

This difference is illustrated in Figure 8 which presents the responses in both core inflation and headline inflation to a permanent shock to inflation. The initial response in core inflation is muted, as the negative temporary shock initially offset the permanent shock. It then takes five months for the actual core inflation rate to adjust to the permanent change. In contrast, headline inflation responds immediately to the long-run shock and, in fact, overshoots the longrun value.

\section{An Unrestricted Unobserved Components Model in Price Levels.}

The last set of models we estimate are for price levels, not inflation rates. This model is appropriate if inflation is I(0), which we find for the 1993-2012 sub-period as well as other subperiods in the latter part of the sample. ${ }^{11}$ When inflation is $\mathrm{I}(0)$, permanent inflation is a constant and economic agents will likely focus on identifying permanent price level movements. We thus apply the unobserved components model to core and headline price levels.

The first model we estimate is similar to the unrestricted bivariate model in inflation rates with the exception that we are modeling the (log) levels of the headline CPI and the core CPI. The results of estimating this model are given in Table 4. Similar to the bivariate model for inflation rates, we find that short-run shocks to both series are negatively correlated with their long-run shocks. We also find that the standard deviation of permanent and temporary shocks to

\footnotetext{
${ }^{11}$ Stationarity tests for core, headline, and food and energy price levels all reject stationarity implying the price series are I(1) for this sub-period.
} 
core inflation are about the same size, but the standard deviation of permanent shocks to headline CPI is three times the size of the standard deviation of its transitory shocks.

This difference is reflected in the graphs of the permanent and temporary components of both series. Figure 9 presents the permanent component of the core CPI along with its actual value. It shows that the permanent component of core CPI is much more variable than the actual series. The relative smoothness of the actual series reflects the negative correlation between the permanent and transitory shocks along with the fact that the transitory shocks are sizeable. That is, not only do transitory shocks tend to offset permanent shocks but they are sufficiently large to smooth the actual series.

This is not the case for headline CPI, as shown in Figure 10. Although the permanent and transitory shocks are negatively correlated, the sizes of the offsetting temporary shocks are too small to cause the headline CPI to be smoother than its permanent component. These latter results suggest that the portion of the CPI that is not included in the core CPI - food and energy prices - has a substantial permanent component.

This leads us to investigate an alternative bivariate model, for the core CPI and a food and energy CPI. ${ }^{12}$ We estimate an unrestricted model which allows the two price series to have different long-run properties, including both different trends and different sequences of permanent shocks. The estimated parameters for this unrestricted price level model are presented in Table 5 and the permanent component for food and energy prices is presented in Figure 11. Key findings from this model are that, as in the previous bivariate model, the core CPI series is

\footnotetext{
12 The Bureau of Labor Statistics (BLS) does not publish a Food \& Energy index (FE), but it does publish separate monthly indices for Food (F), Energy (E), and Core (C). They also provide the weights on these indices for aggregating to the overall CPI. We obtained monthly data on F, E, C, and CPI from the BLS, as well as the annual weights for food, energy, and core that apply to $1987-2012$. We applied the 1987 weights to $1983-1986$. At every point in time, $w_{F} F+w_{E} E+w_{C} C=C P I$, so we construct $\mathrm{FE}$ as $\frac{w_{F}}{\left(1-w_{C}\right)} F+\frac{w_{E}}{\left(1-w_{C}\right)} E=F E$. Note that $\left(1-w_{C}\right) F E+w_{C} C=C P I$, as required.
} 
not correctly characterized as having only permanent movements, and that the food and energy series is not correctly characterized as having just temporary movements.

Our estimates allow us to say something about the standard deviation of the shock to the permanent component of each series, and we find that the core CPI series has a much lower standard deviation than the food and energy series. Thus, we find that the permanent component of the food and energy CPI series experiences much more volatile shocks - has a much higher standard error of shocks to the permanent component - than the permanent component of the core CPI.

In terms of the transitory components, the food and energy series has negative AR parameters indicating its dynamics follow a damped sinusoidal pattern, reflecting overshooting and undershooting. The core series has positive AR parameters. Also, the core series demonstrates a high degree of persistence in its transitory components, with the sum of the AR coefficients being 0.96 .

Our results show that there is an important permanent components to the food and energy series, contradicting the assumption that food and energy prices movements are wholly or largely transitory. This can be seen examining Figure 11 which shows that the permanent component is the main determinant of the actual series.

Another way to look at this issue is to compare the movement in the estimated permanent components with the movement in the actual index for the core and food and energy indices. This can be done by comparing Figures 9 and 11, which show that the permanent component is very important for both series. In fact, close inspection of the figures shows that the permanent component appears to be less important for the core series. Such a conclusion is further supported by comparing the ratio of the variance of the permanent component to the variance of 
the transitory component for both series. This comparison shows that the relative size of the variance of the permanent shocks is smaller for the core series. This stands in contradiction to the assumption that the core series contains permanent price movements while the two excluded series contain mostly temporary price movements. ${ }^{13}$

Ratio of the Standard Error of the
Permanent Shocks to the Standard Error of
the Transitory Shocks
\begin{tabular}{|l|c|}
\hline Core & 0.919 \\
\hline Food \& Energy & 3.114 \\
\hline
\end{tabular}

Important information is also contained in the contemporaneous correlation of the shocks. First, the correlations between the permanent and transitory shocks for an individual series provide insight into the pattern of arrival of shocks to the series. For both core and food and energy, permanent and transitory within-series shocks are highly negatively correlated implying that the full effects of permanent shocks are partially mitigated in the short run. If the adjustment to a permanent shock is somewhat gradual, the actual value in the period of incidence will be below the permanent value, giving rise to a temporary negative shock in the opposite direction. This is consistent with a macroeconomic model including sticky prices.

Cross-series correlations also yield interesting information about the relationship among the shocks to the three series. First, permanent shocks to the core series are correlated with permanent shocks to the food and energy series. We interpret this as suggesting that there may be underlying structural shocks to the food and energy series with permanent components that are related to the permanent movement in the core series.

\footnotetext{
${ }^{13}$ This finding is in stark contrast to the finding in McElroy and Trimbur (2012) who find a high signal to noise ratio for core, but their model, like most others, assumes zero correlation between permanent and temporary shocks.
} 
In sum, when inflation is $\mathrm{I}(0)$, permanent inflation is a constant, but the price level appears to experience volatile permanent shocks. These permanent movements in the overall price level are not well captured by core CPI for two reasons: 1) permanent shocks to core are volatile but offset by temporary shocks such that the core series appears more smooth than its permanent component and 2) food and energy prices experience permanent movements not captured in the core price series.

\section{F. Conclusion}

We examine the utility of core inflation as a measure of permanent inflation through the estimation of a series of unobserved components models. Although we find some evidence supporting the use of core inflation, we also find some important concerns about its use. This leads us to the following conclusions.

First, the utility of core inflation critically depends upon the existence of a cointegrating relationship between headline inflation and core inflation. However, the results from testing this relationship are mixed and change depending upon the test used and time period studied. Moreover, the evidence for even the non-stationarity of inflation is mixed. This result suggests that it is important to consider both inflation models and price level models and we estimate both types.

Second, we estimate both unrestricted and common trend unobserved components models for core inflation and headline inflation. From the unrestricted model, we find permanent shocks to core inflation have a larger variance than the permanent shocks to headline inflation, particularly for more recent years. This undermines the utility of core inflation as a measure of permanent price changes. We also find that actual core inflation is smoother than permanent core inflation. This is because there is a strong negative correlation between transitory and 
permanent shocks to core inflation. This is consistent with short-run sticky prices for the items included in core inflation. In addition, we find that actual core inflation is more variable than the permanent component of headline inflation and we find some evidence that suggests that core inflation may overstate (during periods of relatively high inflation) or understate (during periods of relatively low inflation) the true permanent component of inflation. Thus it could provide a misleading signal to policymakers. Finally, we find that the short-run dynamics of core inflation indicate that it is slow to adjust to permanent shocks. This could lead policymakers using core inflation as a measure of permanent inflation to react too slowly to permanent shocks.

Third, the restricted unobserved components model provides evidence more favorable for the use of core inflation as a measure of permanent price changes because, by construction, the permanent part of core and the permanent part of headline inflation are specified to be same. Nevertheless, we find that actual core inflation is smoother than its permanent component because of a negative correlation between permanent core inflation shocks and temporary core shocks and because of a slow adjustment in core inflation to permanent shocks. This reduces the usefulness of actual core inflation as a measure of permanent inflation.

Fourth, because we find evidence that inflation may be stationary over the last twenty years, we estimate an unobserved components model in prices levels for that recent sub-period. We find that, contrary to "common wisdom," the core CPI series is not correctly characterized as having only permanent movements, and the food and energy series not correctly characterized as having just temporary movements. Furthermore, the temporary movements in core CPI regularly offset permanent movements, so shocks to the permanent component of core CPI are actually more volatile than the shocks to the observed series. These results also raise concerns about the use of core CPI as the basis for measuring permanent price changes. 
Table 1: Stationarity and Cointegration Test Results

\author{
$\underline{\text { Stationarity Tests }}$
}

Sample 1984 - 2012

\begin{tabular}{|c|c|c|c|c|c|}
\hline $\begin{array}{c}\text { Inflation } \\
\text { Series } \\
\end{array}$ & $\begin{array}{l}\text { KPSS test } \\
\text { statistic }\end{array}$ & $\begin{array}{l}\text { MPS test } \\
\text { statistic }\end{array}$ & $\begin{array}{c}\text { ADF test } \\
\text { statistic }\end{array}$ & $\begin{array}{l}\text { PP test } \\
\text { statistic }\end{array}$ & Conclusion \\
\hline \multicolumn{6}{|c|}{ Year-on-Year Changes } \\
\hline $\begin{array}{c}100 *(\ln (\mathbf{C P I})- \\
\ln (\mathrm{CPI}(-12)))\end{array}$ & $\begin{array}{c}0.07 \\
(p=0.60) \\
\text { Supports } \mathrm{I}(0)\end{array}$ & $\begin{array}{c}1.61 \\
(p=0.06) \\
\text { Supports } \mathrm{I}(1)\end{array}$ & $\begin{array}{c}-3.39 \\
(p=0.05) \\
\text { Supports } \mathrm{I}(0)\end{array}$ & $\begin{array}{c}-4.01 \\
(p=0.01) \\
\text { Supports } I(0)\end{array}$ & Mixed \\
\hline $\begin{array}{c}100 *(\ln (\text { Core })- \\
\ln (\text { Core }(-12)))\end{array}$ & $\begin{array}{c}0.20 \\
(p=0.38) \\
\text { Supports } \mathrm{I}(0)\end{array}$ & $\begin{array}{c}34.73 \\
(p<0.01) \\
\text { Supports I }(1)\end{array}$ & $\begin{array}{c}-1.94 \\
(p=0.63) \\
\text { Supports } I(1)\end{array}$ & $\begin{array}{c}-2.55 \\
(p=0.31) \\
\text { Supports } I(1)\end{array}$ & $\mathrm{I}(1)$ \\
\hline $\begin{array}{l}100 *(\ln (\mathbf{F E})- \\
\ln (\mathrm{FE}(-12)))\end{array}$ & $\begin{array}{c}0.041 \\
(p=0.94) \\
\text { Supports } \mathrm{I}(0)\end{array}$ & $\begin{array}{c}0.79 \\
(p=0.07) \\
\text { Supports } I(1)\end{array}$ & $\begin{array}{c}-4.74 \\
(p<0.01) \\
\text { Supports } \mathrm{I}(0)\end{array}$ & $\begin{array}{c}-4.39 \\
(\mathrm{p}<0.01) \\
\text { Supports } \mathrm{I}(0)\end{array}$ & Mixed \\
\hline
\end{tabular}

Sample 1993 - 2012

\begin{tabular}{|c|c|c|c|c|c|}
\hline $\begin{array}{c}\text { Inflation } \\
\text { Series }\end{array}$ & $\begin{array}{c}\text { KPSS test } \\
\text { statistic }\end{array}$ & $\begin{array}{l}\text { MPS test } \\
\text { statistic }\end{array}$ & $\begin{array}{c}\text { ADF test } \\
\text { statistic }\end{array}$ & $\begin{array}{l}\text { PP test } \\
\text { statistic }\end{array}$ & Conclusion \\
\hline \multicolumn{6}{|c|}{ Year-on-Year Changes } \\
\hline $\begin{array}{c}100 *(\ln (\mathbf{C P I})- \\
\ln (\mathrm{CPI}(-12)))\end{array}$ & $\begin{array}{c}0.06 \\
(p=0.80) \\
\text { Supports } \mathrm{I}(0)\end{array}$ & $\begin{array}{c}0.64 \\
(p=0.12) \\
\text { Supports } \mathrm{I}(0)\end{array}$ & $\begin{array}{c}-2.54 \\
(p=0.31) \\
\text { Supports } I(1)\end{array}$ & $\begin{array}{c}-3.80 \\
(p=0.02) \\
\text { Supports } I(0)\end{array}$ & Mixed \\
\hline $\begin{array}{c}100 *(\ln (\text { Core })- \\
\ln (\text { Core }(-12)))\end{array}$ & $\begin{array}{c}0.08 \\
(p=0.91) \\
\text { Supports } \mathrm{I}(0)\end{array}$ & $\begin{array}{c}2.43 \\
(p=0.26) \\
\text { Supports } \mathrm{I}(0)\end{array}$ & $\begin{array}{c}-2.60 \\
(p=0.28) \\
\text { Supports } I(1)\end{array}$ & $\begin{array}{c}-2.71 \\
(p=0.24) \\
\text { Supports } I(1)\end{array}$ & Mixed \\
\hline $\begin{array}{l}100 *(\ln (\mathbf{F E})- \\
\ln (\mathrm{FE}(-12)))\end{array}$ & $\begin{array}{c}0.05 \\
(p=0.84) \\
\text { Supports } \mathrm{I}(0)\end{array}$ & $\begin{array}{c}0.62 \\
(p=0.10) \\
\text { Supports } \mathrm{I}(0)\end{array}$ & $\begin{array}{c}-3.50 \\
(p=0.04) \\
\text { Supports } \mathrm{I}(0)\end{array}$ & $\begin{array}{c}-3.96 \\
(p=0.01) \\
\text { Supports } I(0)\end{array}$ & $\mathrm{I}(0)$ \\
\hline
\end{tabular}

Johansen Cointegration Tests, Core Inflation and CPI Inflation

Sample 1984-2012

\begin{tabular}{|c|c|c|c|}
\hline $\begin{array}{c}\text { Hypothesized Number of } \\
\text { Cointegrating Vectors }\end{array}$ & $\begin{array}{c}\text { Trace Test } \\
\text { Statistic }\end{array}$ & P-Value & Conclusion \\
\hline 0 & 23.17 & $<0.01$ & One cointegrating vector, $<1,-1.34>$ \\
1 & 1.92 & 0.17 & $1.00 \cdot \pi_{\text {core }}-1.34 \cdot \pi_{C P I} \sim I(0)$ \\
\hline 1 & &
\end{tabular}

Sample 1993-2012

\begin{tabular}{|c|c|c|c|}
\hline $\begin{array}{c}\text { Hypothesized Number of } \\
\text { Cointegrating Vectors }\end{array}$ & $\begin{array}{c}\text { Trace Test } \\
\text { Statistic }\end{array}$ & P-Value & Conclusion \\
\hline 0 & 35.83 & $<0.01$ & \multirow{2}{*}{$\begin{array}{c}\text { Two cointegrating vectors; supports } \\
\text { conclusion that series are stationary }\end{array}$} \\
\hline 1 & 5.36 & 0.02 & \\
\hline
\end{tabular}

Table 2: Unrestricted Bivariate Model Core Inflation and Headline Inflation 
Parameter Estimates ( 1 = core inflation, 2 = headline inflation $)$

\begin{tabular}{|c|c|c|}
\hline & Parameters & $\begin{array}{c}\text { Std. } \\
\text { Dev. }\end{array}$ \\
\hline$\sigma_{\eta_{1}}$ & 0.167 & 0.009 \\
\hline$\sigma_{\eta_{2}}$ & 0.105 & 0.029 \\
\hline$\sigma_{\varepsilon_{1}}$ & 0.047 & 0.016 \\
\hline$\sigma_{\varepsilon_{2}}$ & 0.416 & 0.040 \\
\hline$\mu_{1}$ & -0.008 & 0.009 \\
\hline$\mu_{2}$ & -0.004 & 0.006 \\
\hline$\phi_{11}$ & 1.553 & 0.038 \\
\hline$\phi_{21}$ & -0.719 & 0.031 \\
\hline$\phi_{12}$ & 1.281 & 0.055 \\
\hline$\phi_{22}$ & -0.393 & 0.055 \\
\hline Log Likelihood Value & \multicolumn{2}{|c|}{114.718} \\
\hline
\end{tabular}

Correlations among the Permanent and Transitory Shocks

\begin{tabular}{|c|c|c|}
\hline & Correlation & $\begin{array}{c}\text { Std. } \\
\text { Dev. }\end{array}$ \\
\hline$\rho_{\eta_{1} \eta_{2}}$ & 0.601 & 0.342 \\
\hline$\rho_{\eta_{1} \varepsilon_{1}}$ & -0.936 & 0.036 \\
\hline$\rho_{\eta_{1} \varepsilon_{2}}$ & -0.019 & 0.051 \\
\hline$\rho_{\eta_{2} \varepsilon_{1}}$ & -0.834 & 0.236 \\
\hline$\rho_{\eta_{2} \varepsilon_{2}}$ & -0.810 & 0.225 \\
\hline$\rho_{\varepsilon_{1} \varepsilon_{2}}$ & 0.356 & 0.110 \\
\hline
\end{tabular}


Table 3: Restricted Bivariate Model Core Inflation and Headline Inflation

Parameter Estimates ( 1 = core inflation, 2 = headline inflation)

\begin{tabular}{|c|c|c|}
\hline & Parameters & $\begin{array}{c}\text { Std. } \\
\text { Dev. }\end{array}$ \\
\hline$\sigma_{\eta}^{2}$ & 0.141 & 0.014 \\
\hline$\sigma_{\varepsilon_{1}}$ & 0.131 & 0.032 \\
\hline$\sigma_{\varepsilon_{2}}$ & 0.281 & 0.020 \\
\hline$\phi_{11}$ & 0.425 & 0.209 \\
\hline$\phi_{21}$ & -0.003 & 0.076 \\
\hline$\phi_{12}$ & 1.431 & 0.062 \\
\hline$\phi_{22}$ & -0.520 & 0.060 \\
\hline$\gamma$ & 0.978 & .054 \\
\hline Log Likelihood Value & \multicolumn{2}{|c}{100.367} \\
\hline
\end{tabular}

Correlations among the Permanent and Transitory Shocks

\begin{tabular}{|c|c|c|}
\hline & Correlation & $\begin{array}{c}\text { Std. } \\
\text { Dev. }\end{array}$ \\
\hline$\rho_{\eta_{\varepsilon_{1}}}$ & -0.720 & 0.144 \\
\hline$\rho_{\eta \varepsilon_{2}}$ & 0.309 & 0.114 \\
\hline$\rho_{\varepsilon_{1} \varepsilon_{2}}$ & -0.095 & 0.181 \\
\hline
\end{tabular}

Note that we found that $\mu=0$ so it is excluded from the final estimates. 
Table 4: Unrestricted Bivariate Model in Core and CPI Prices

Parameter Estimates ( 1 = Core prices, 2 = CPI prices $)$

Sample Period 1993-2012

\begin{tabular}{|c|c|c|}
\hline & Parameters & $\begin{array}{c}\text { Std. } \\
\text { Dev. }\end{array}$ \\
\hline$\sigma_{\eta_{1}}$ & 0.307 & 0.029 \\
\hline$\sigma_{\eta_{2}}$ & 0.350 & 0.023 \\
\hline$\sigma_{\varepsilon_{1}}$ & 0.319 & 0.024 \\
\hline$\sigma_{\varepsilon_{2}}$ & 0.104 & 0.014 \\
\hline$\mu_{1}$ & 0.165 & 0.021 \\
\hline$\mu_{2}$ & 0.200 & 0.023 \\
\hline$\phi_{11}$ & 0.942 & 0.018 \\
\hline$\phi_{21}$ & 0.023 & 0.017 \\
\hline$\phi_{12}$ & -0.262 & 0.042 \\
\hline$\phi_{22}$ & -0.275 & 0.048 \\
\hline Log Likelihood Value & \multicolumn{2}{|c|}{250.085} \\
\hline
\end{tabular}

Correlations among the Permanent and Transitory Shocks

\begin{tabular}{|c|c|c|}
\hline & Correlation & $\begin{array}{c}\text { Std. } \\
\text { Dev. }\end{array}$ \\
\hline$\rho_{\eta_{1} \eta_{2}}$ & 0.871 & 0.053 \\
\hline$\rho_{\eta_{1} \varepsilon_{1}}$ & -0.971 & 0.005 \\
\hline$\rho_{\eta_{1} \varepsilon_{2}}$ & -0.849 & 0.058 \\
\hline$\rho_{\eta_{2} \varepsilon_{1}}$ & -0.795 & 0.039 \\
\hline$\rho_{\eta_{2} \varepsilon_{2}}$ & -0.987 & 0.027 \\
\hline$\rho_{\varepsilon_{1} \varepsilon_{2}}$ & 0.806 & 0.053 \\
\hline
\end{tabular}


Table 5: Unrestricted Bivariate Model in Core and Food\& Energy Prices

Parameter Estimates ( 1 = Core prices, 2 = Food \& Energy prices)

Sample Period 1993-2012

\begin{tabular}{|c|c|c|}
\hline & Parameters & $\begin{array}{c}\text { Std. } \\
\text { Dev. }\end{array}$ \\
\hline$\sigma_{\eta_{1}}$ & 0.344 & 0.199 \\
\hline$\sigma_{\eta_{2}}$ & 1.368 & 0.144 \\
\hline$\sigma_{\varepsilon_{1}}$ & 0.365 & 0.270 \\
\hline$\sigma_{\varepsilon_{2}}$ & 0.437 & 0.044 \\
\hline$\mu_{1}$ & 0.166 & 0.023 \\
\hline$\mu_{2}$ & 0.267 & 0.095 \\
\hline$\phi_{11}$ & 0.931 & 0.074 \\
\hline$\phi_{21}$ & 0.034 & 0.058 \\
\hline$\phi_{12}$ & -0.267 & 0.124 \\
\hline$\phi_{22}$ & -0.316 & 0.102 \\
\hline Log Likelihood Value & \multicolumn{2}{|c}{-66.806} \\
\hline \multicolumn{2}{|c|}{} \\
\hline
\end{tabular}

Correlations among the Permanent and Transitory Shocks

\begin{tabular}{|c|c|c|}
\hline & Correlation & $\begin{array}{c}\text { Std. } \\
\text { Dev. }\end{array}$ \\
\hline$\rho_{\eta_{1} \eta_{2}}$ & 0.582 & 0.235 \\
\hline$\rho_{\eta_{1} \varepsilon_{1}}$ & -0.980 & 0.041 \\
\hline$\rho_{\eta_{1} \varepsilon_{2}}$ & -0.386 & 0.057 \\
\hline$\rho_{\eta_{2} \varepsilon_{1}}$ & -0.547 & 0.155 \\
\hline$\rho_{\eta_{2} \varepsilon_{2}}$ & -0.972 & 0.074 \\
\hline$\rho_{\varepsilon_{1} \varepsilon_{2}}$ & 0.365 & 0.040 \\
\hline
\end{tabular}


Figure 1. CPI Inflation Series: Headline and Core

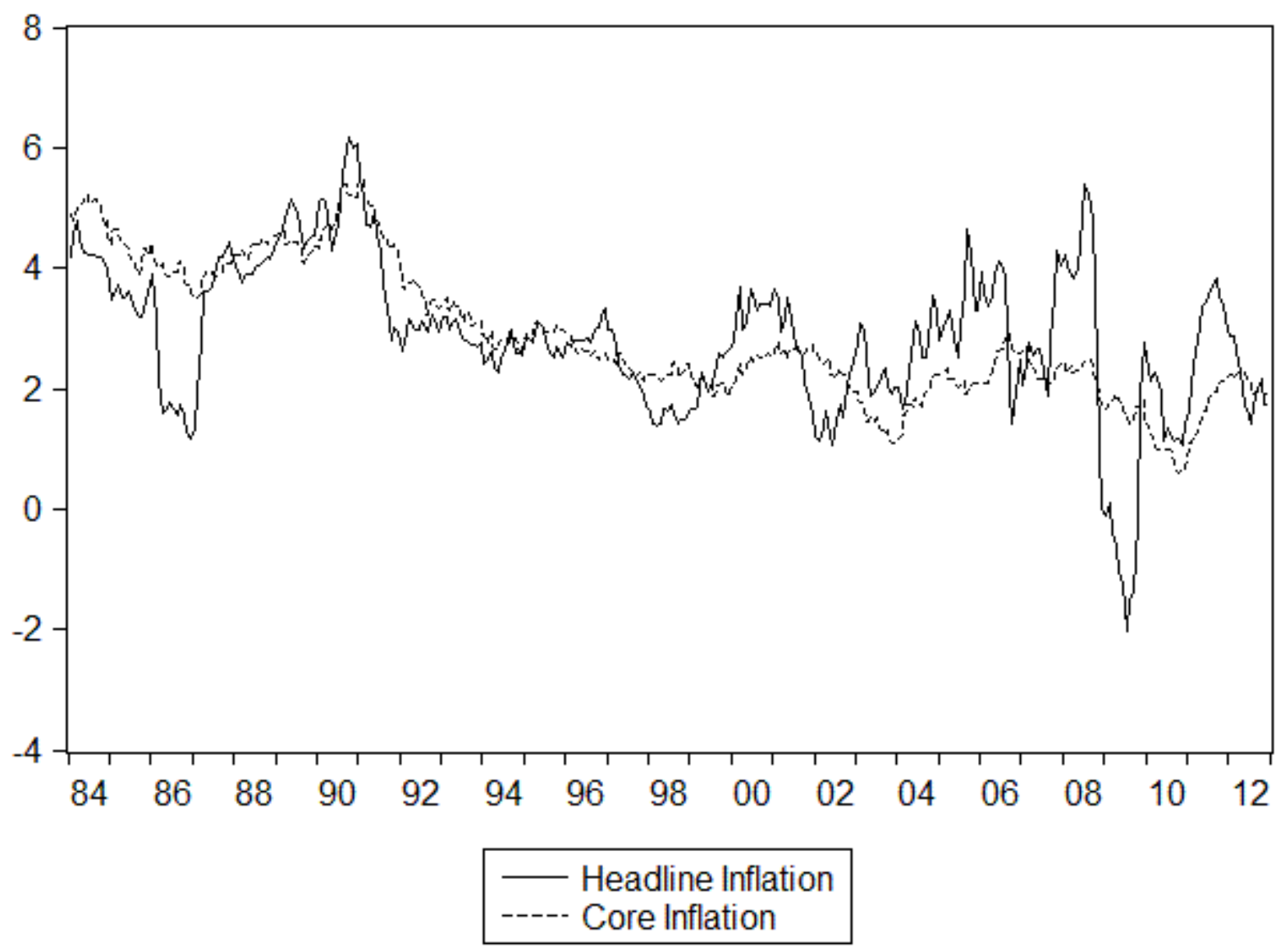


Figure 2. Headline Inflation and the Permanent Component of Headline Inflation from a Univariate Model

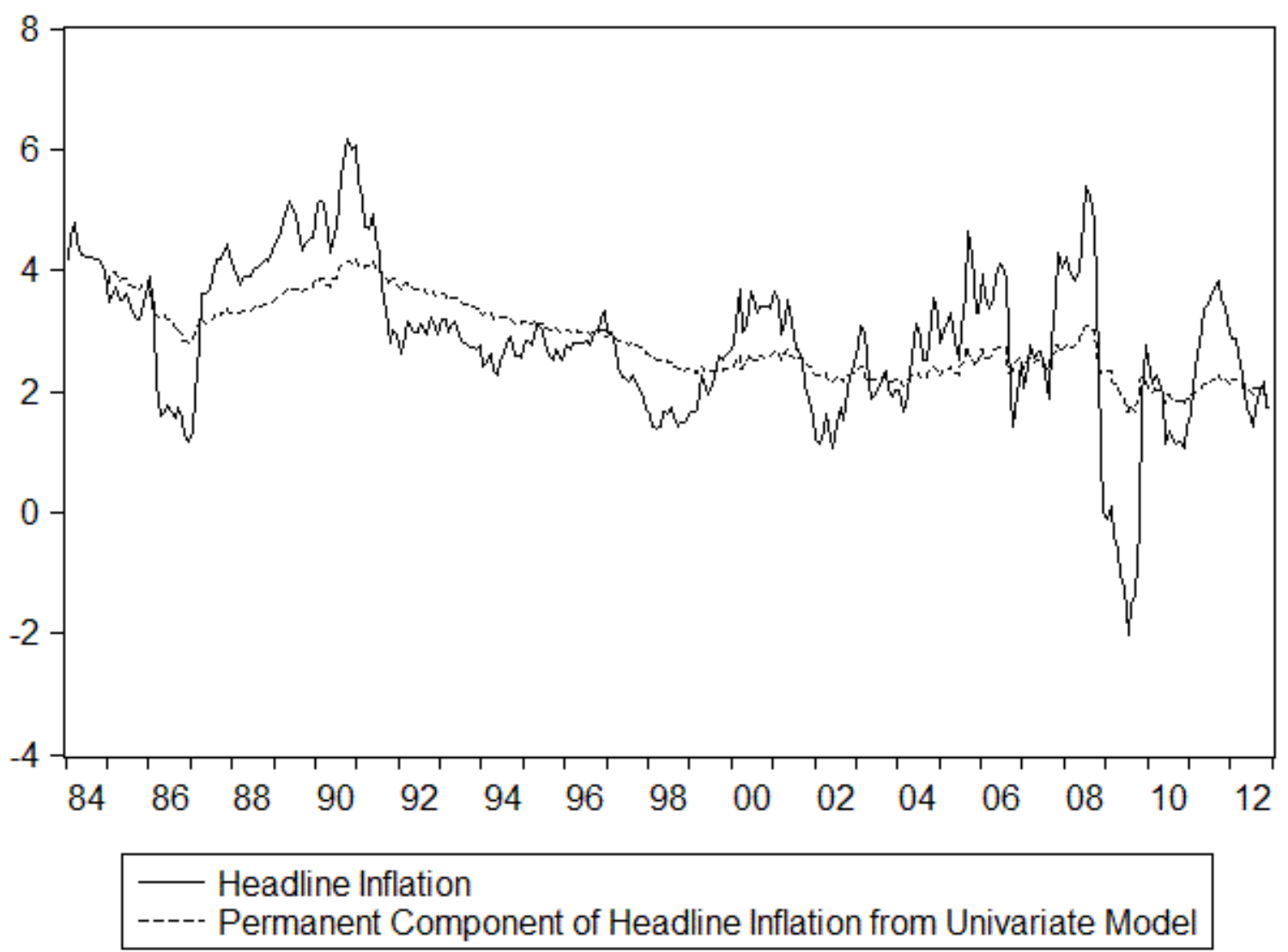


Figure 3. Core Inflation and the Permanent Component of Headline Inflation from A Univariate Model

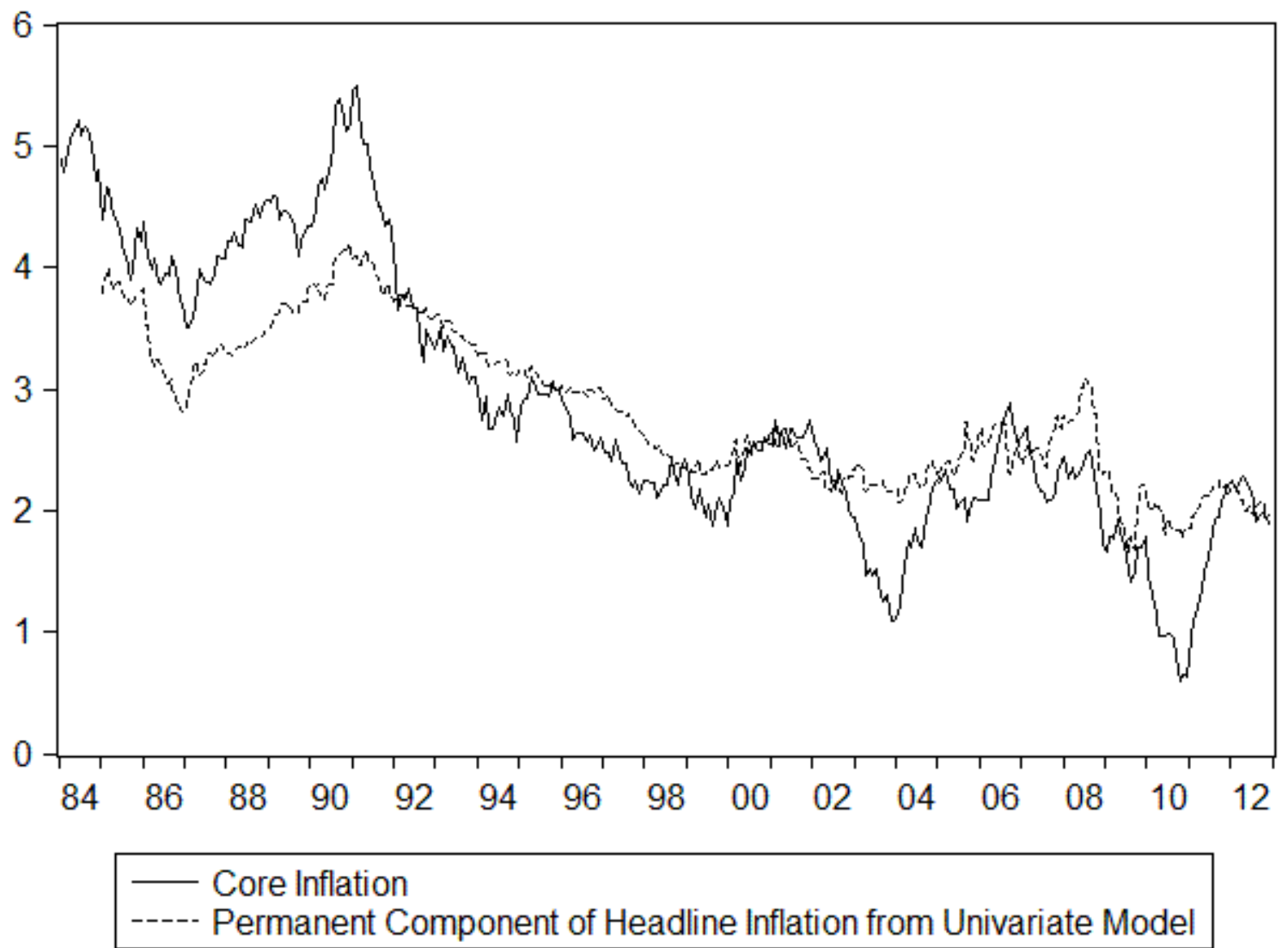


Figure 4. Permanent Components from the Unrestricted Bivariate Model (no cointegration) Graph of Headline Inflation, Actual Series and Permanent Component

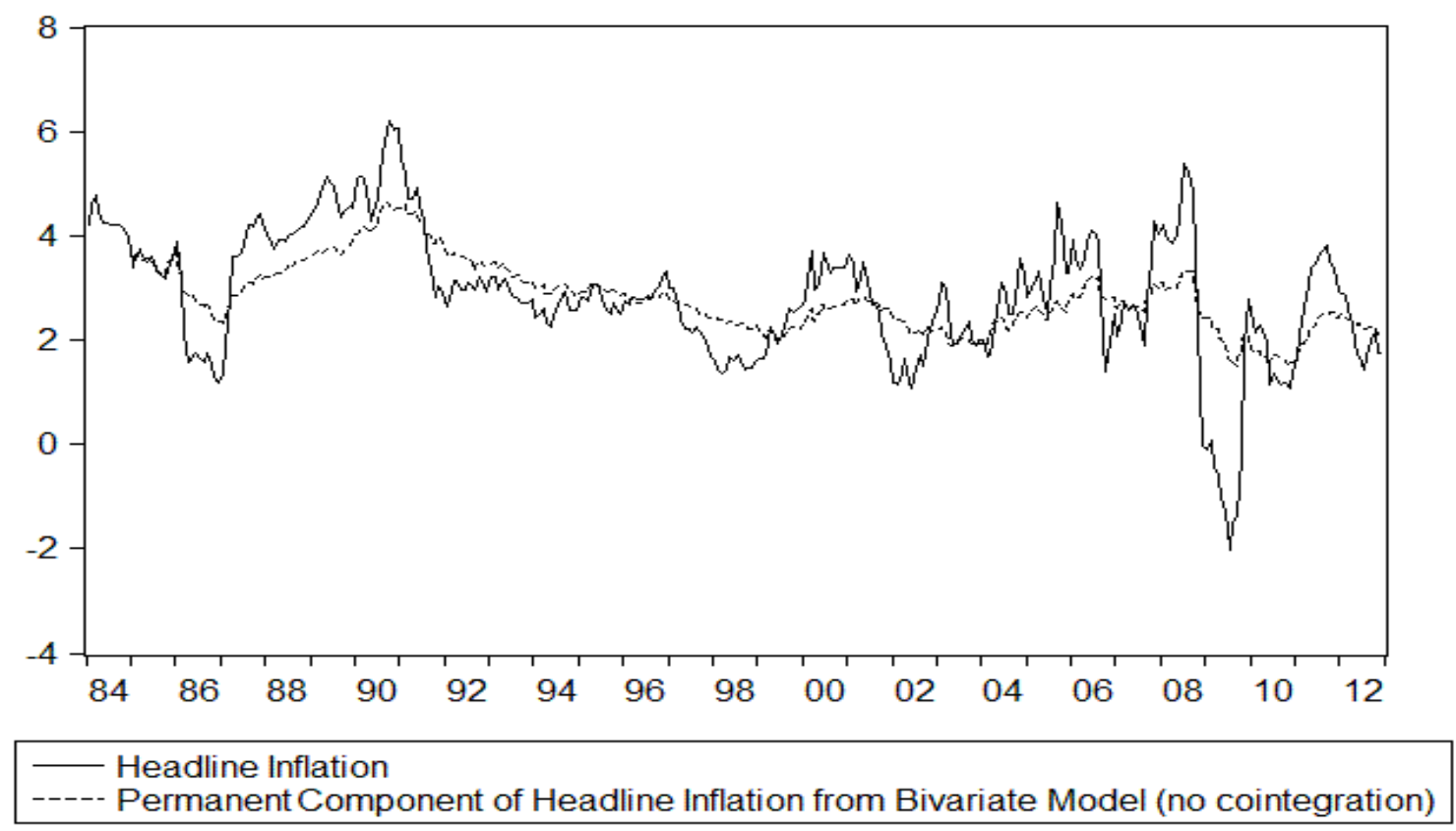

Graph of Core Inflation, Actual Series and Permanent Component

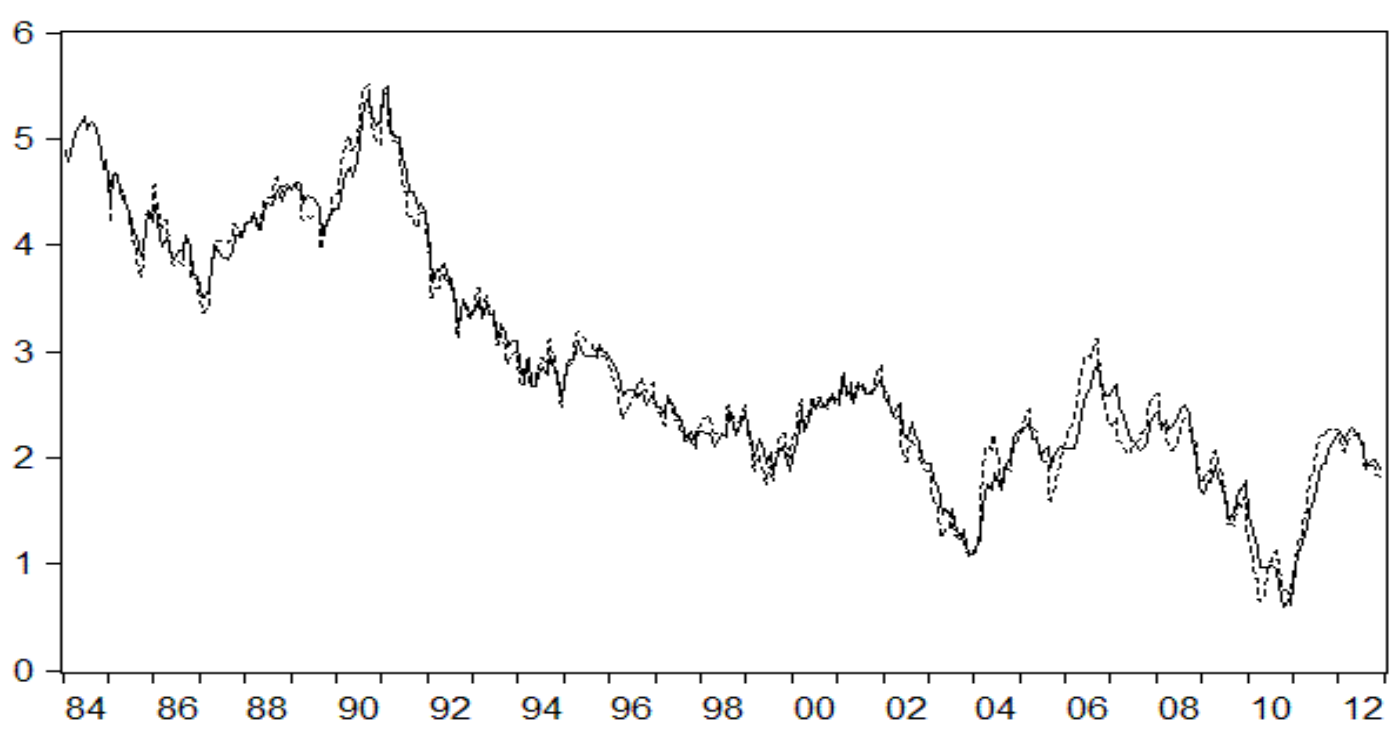

Core Inflation

----- Permanent Component of Core Inflation from Bivariate Model (no cointegration) 
Figure 5. Unrestricted Bivariate Model (no cointegration):

Permanent Components of Headline Inflation and Core Inflation

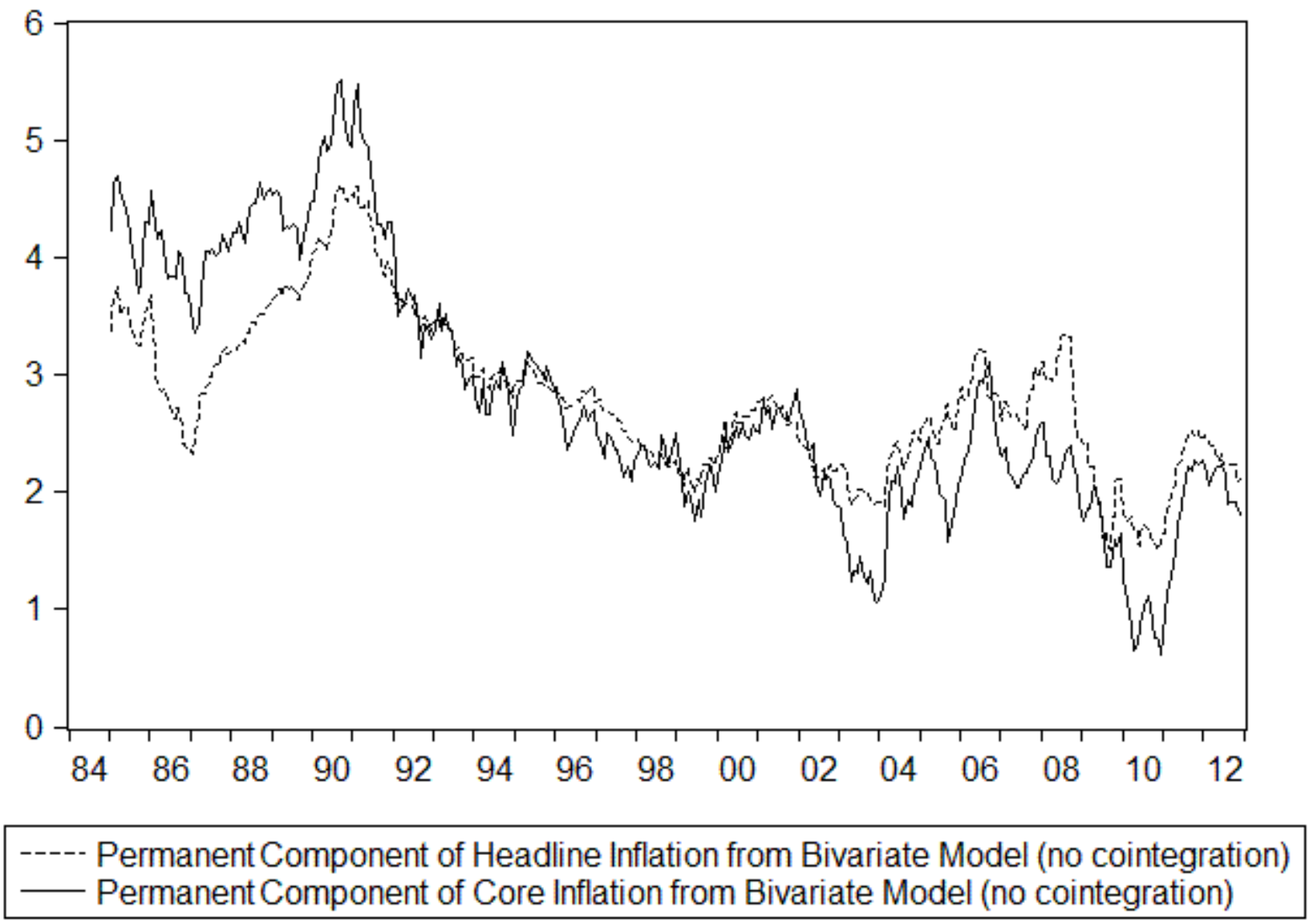


Figure 6. Simulated Impact of a Shock to the Permanent Component of Core Inflation on Core Inflation in the Unrestricted Bivariate Model (no cointegration).

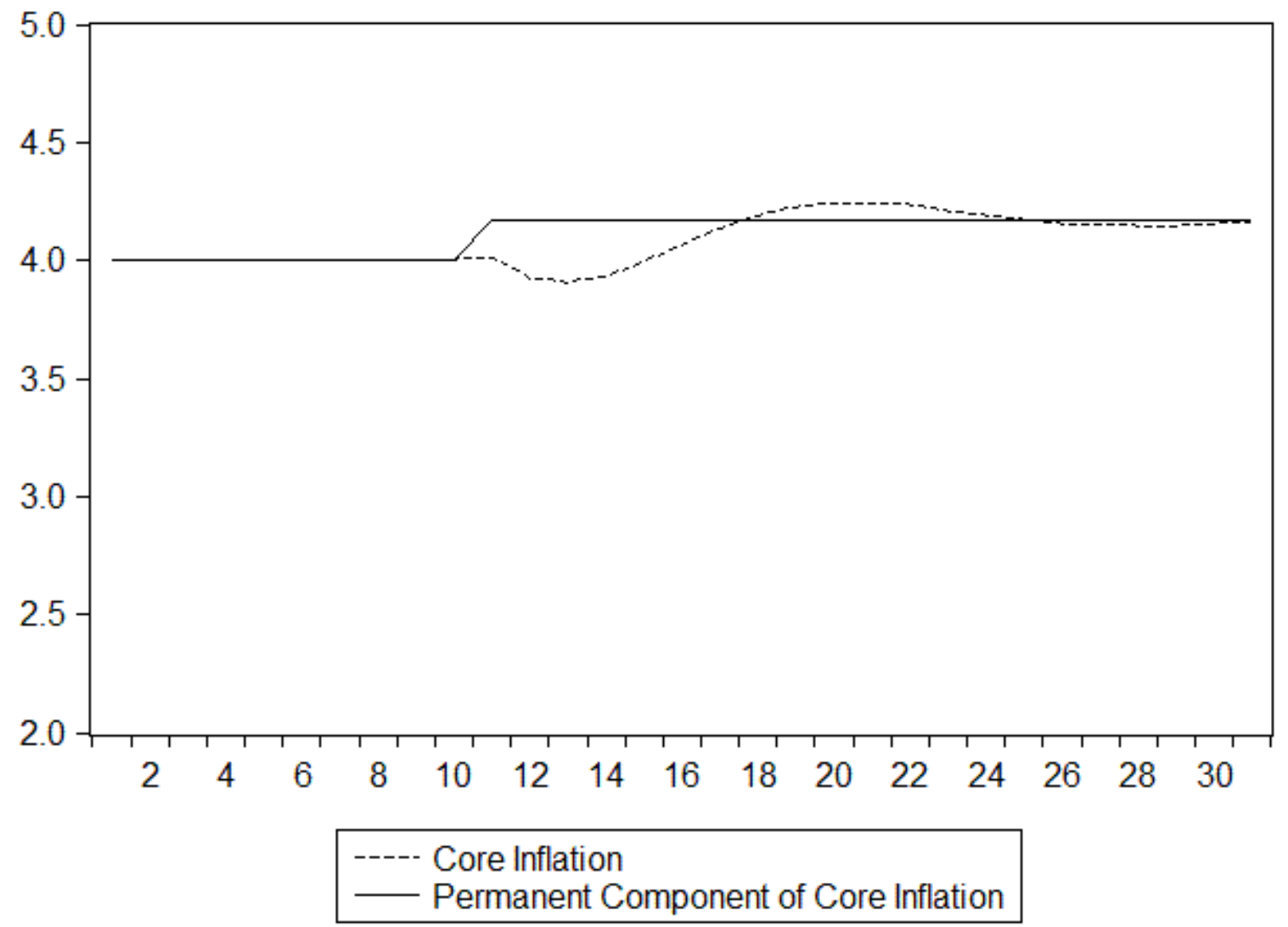


Figure 7. Permanent Components from the Restricted Bivariate Model (with cointegration) Graph of Headline Inflation and Permanent Component

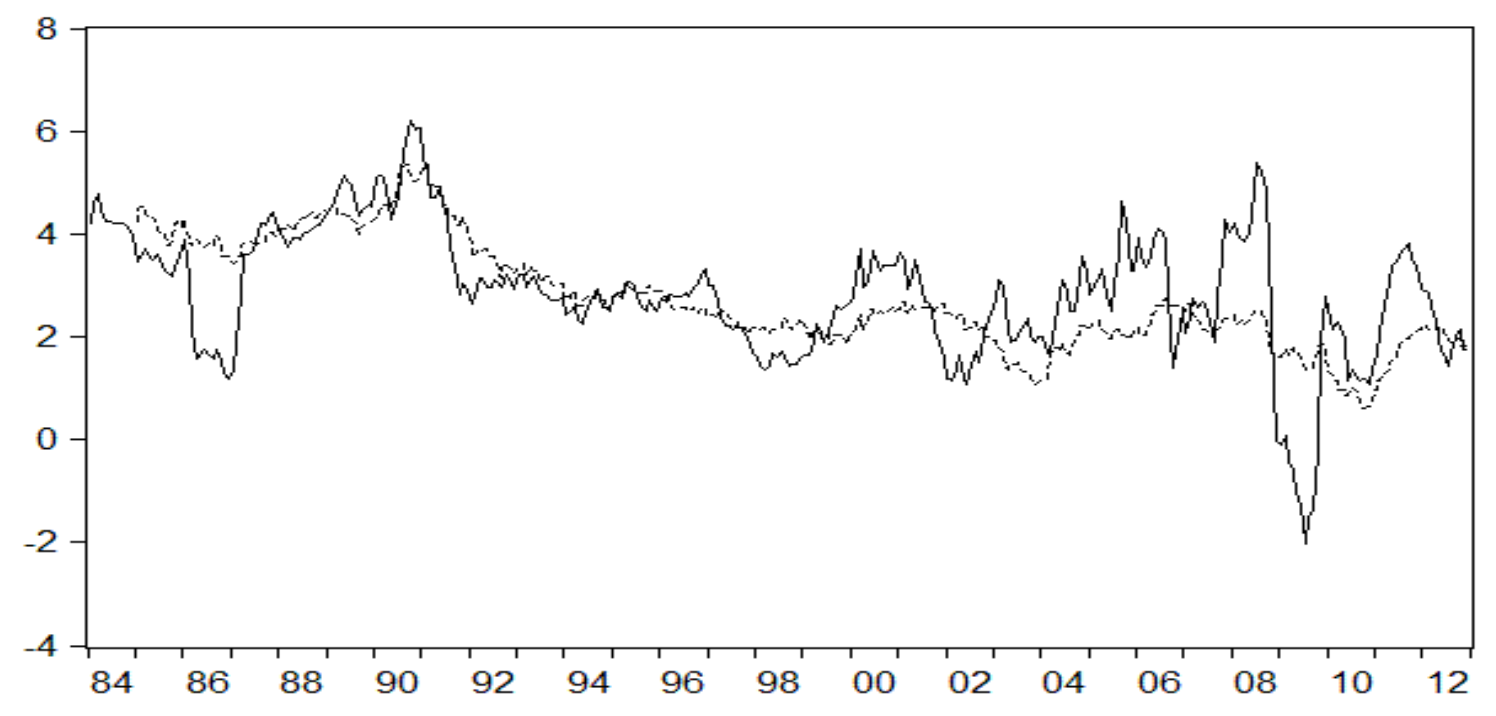

Headline Inflation

----- Permanent Component of Headline Inflation from Bivariate Model (with cointegration)

Graph of Core Inflation and Permanent Component

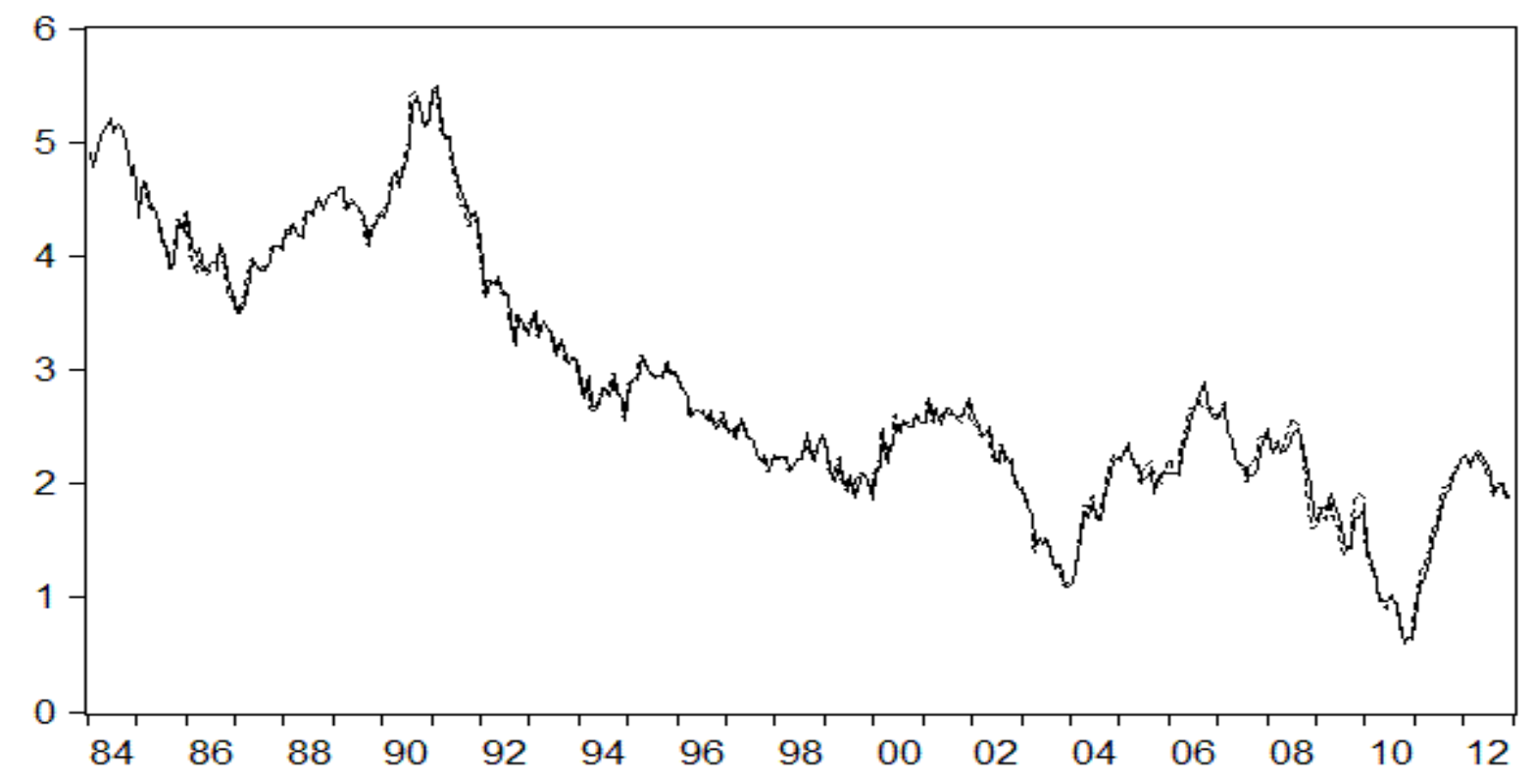


Figure 8. Simulated Impact of a Shock to the Permanent Component of Core Inflation on Core Inflation (bottom) and Headline Inflation (top) in the Restricted Bivariate Model (with cointegration)

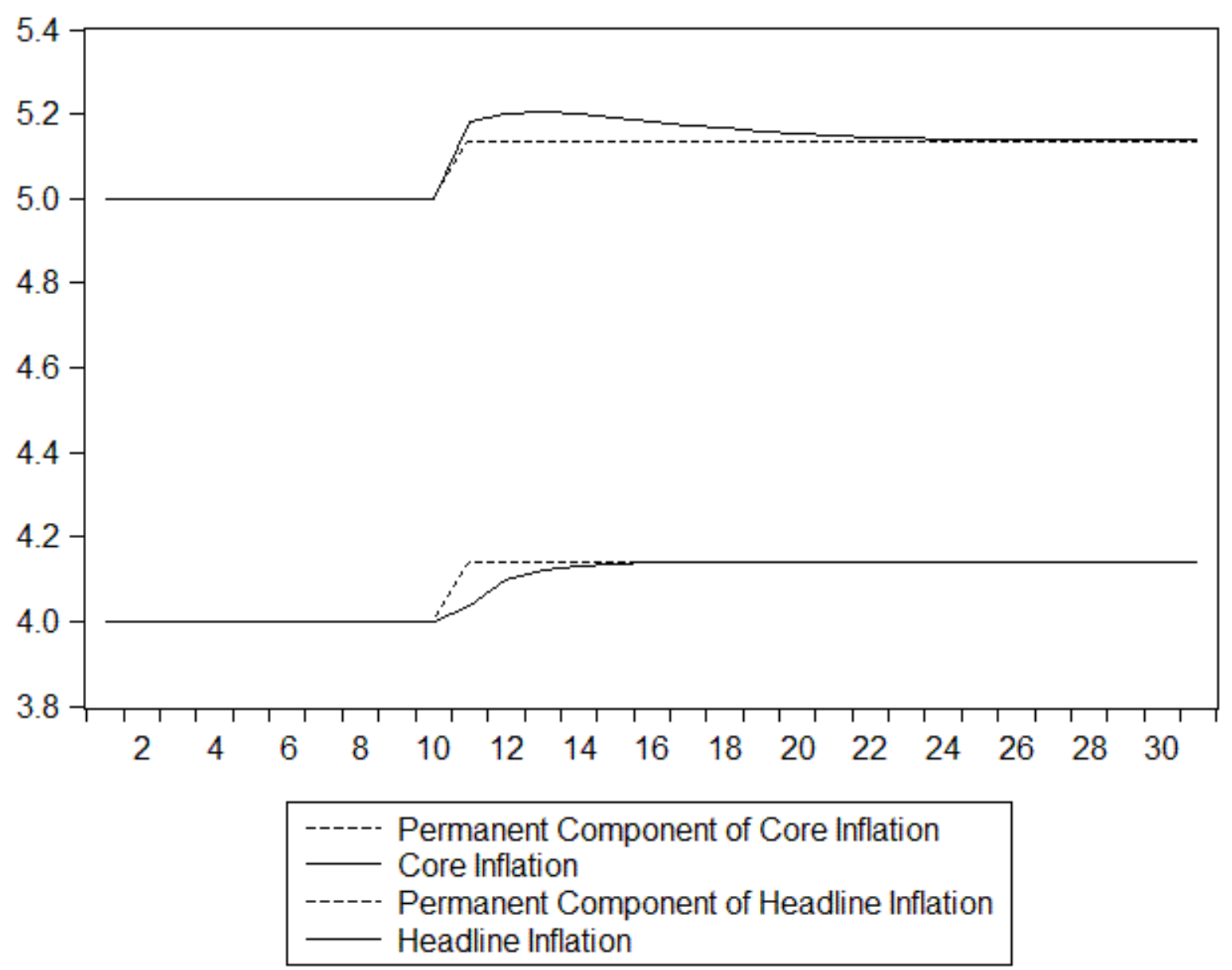


Figure 9. Core CPI and the Permanent Component of Core CPI from a Bivariate Model in Core CPI and Headline CPI

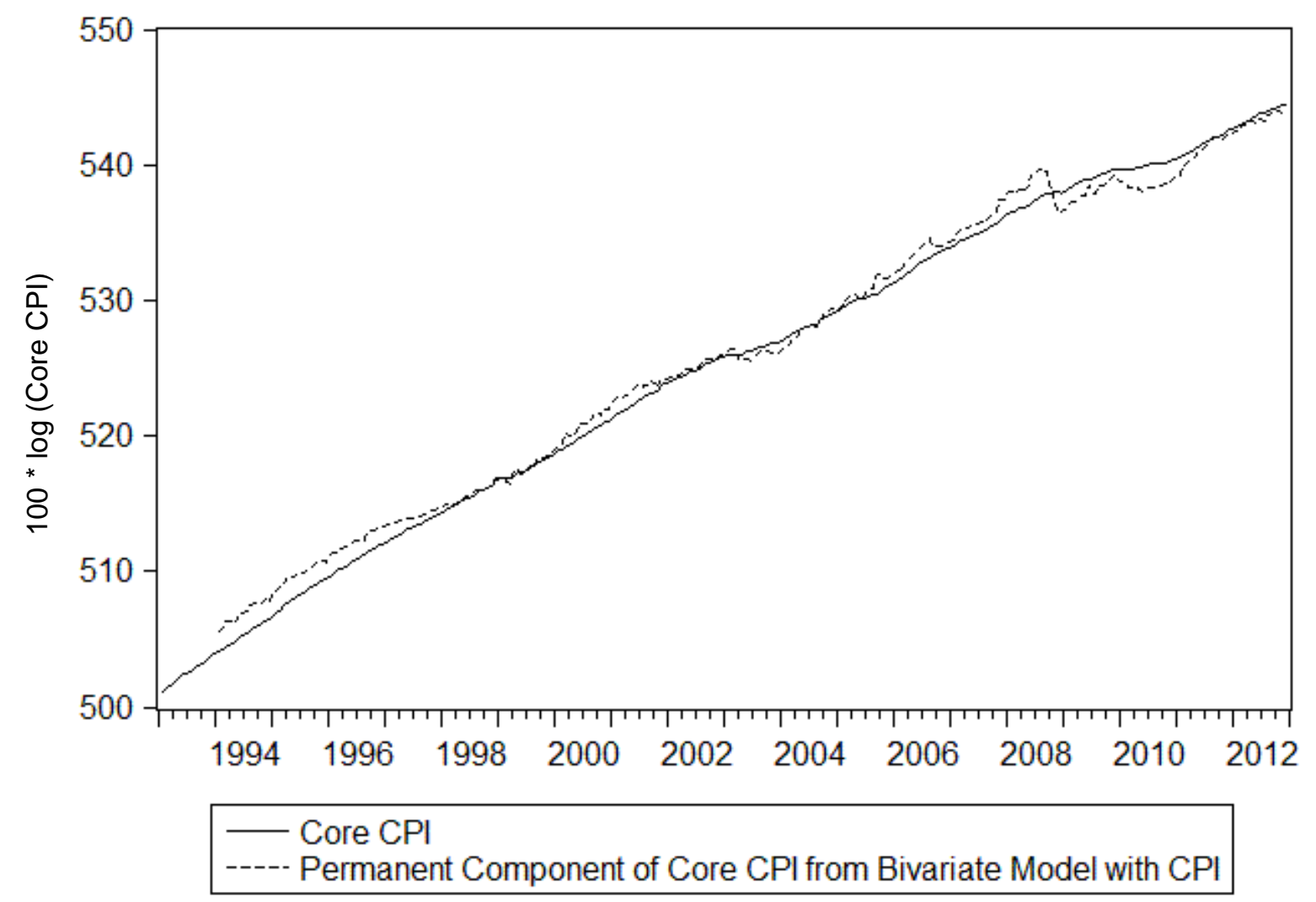


Figure 10. Headline CPI and the Permanent Component of Headline CPI from a Bivariate Model in Core CPI and Headline CPI

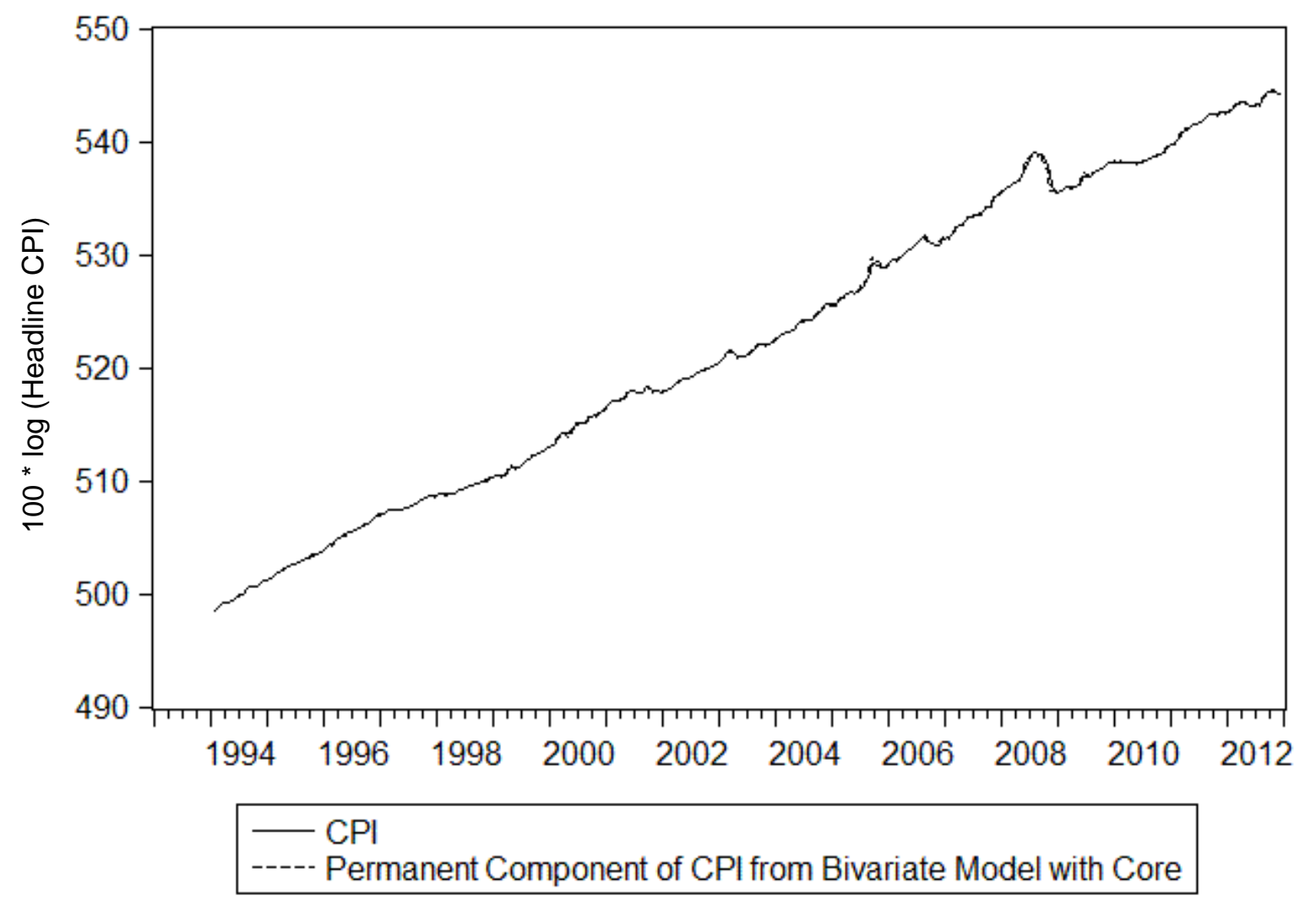


Figure 11. Food and Energy CPI and the Permanent Component of Food and Energy CPI from a Bivariate Model in Core CPI and Food \& Energy CPI

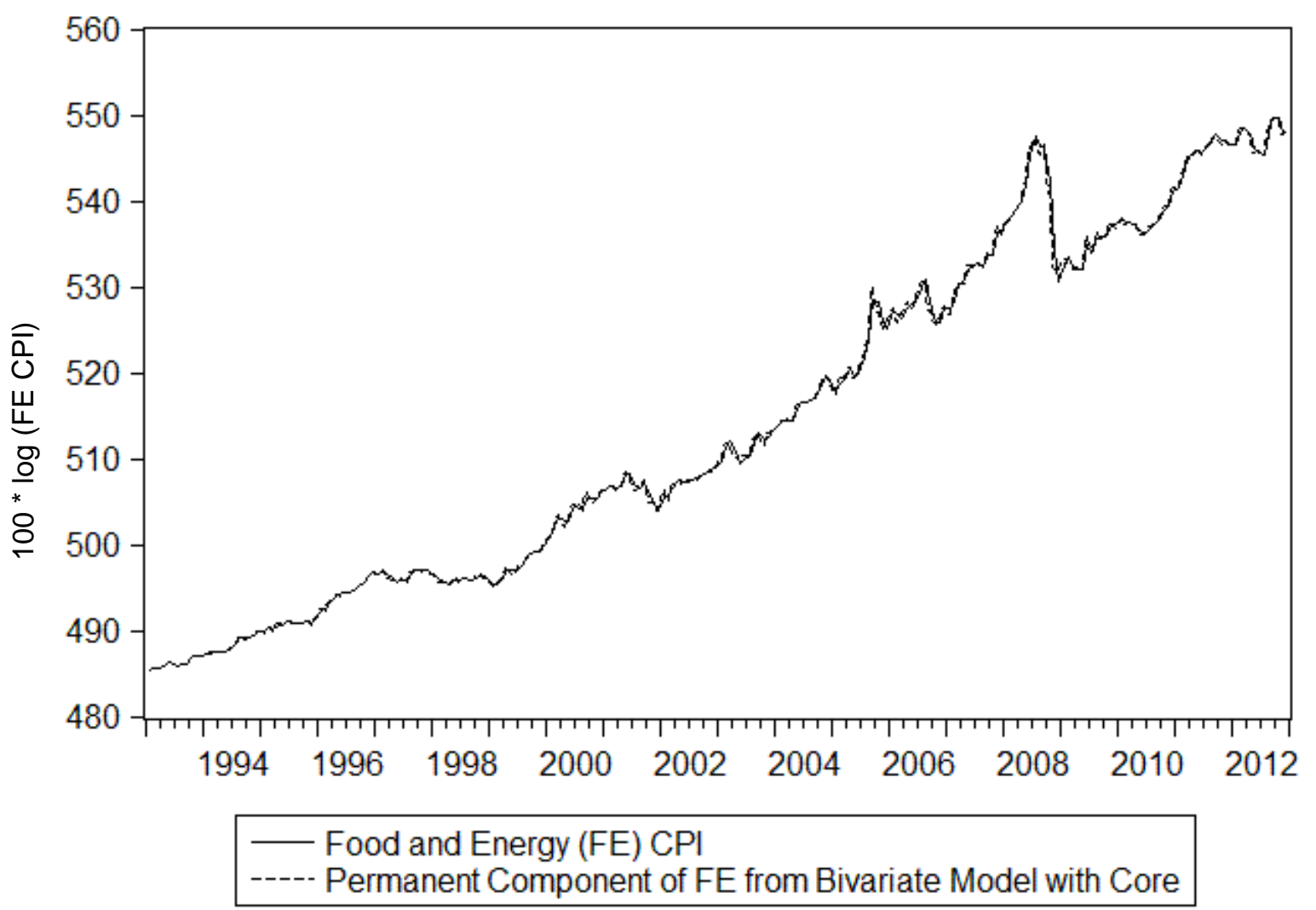




\section{References}

Bhatt, Vipul and N. Kundan Kishor. Are All Movements in Food and Energy Prices Transitory? Evidence from India” Working Paper. Available at:

http://cob.jmu.edu/bhatt/Inflation\%20Dynamics_Final.pdf.

Beveridge, Stephen and Charles R. Nelson (1981) A New Approach to Decomposition of Economic Time Series into Permanent and Transitory Components with Particular Attention to Measurement of the Business Cycle. Journal of Monetary Economics 7.2, 151-174.

Bodenstein, Martin, Christopher J. Erceg, and Luca Guerrieri (2008) Optimal Monetary Policy with Distinct Core and Headline Inflation Rates. Journal of Monetary Economics 55, S18-S33.

Bradley, Michael D. and Dennis W. Jansen, (1986) Federal Reserve Operating Procedure in the Eighties: A Dynamic Analysis. Journal of Money, Credit, and Banking Vol. 18(3), 323-335

Bullard, James (2011) Measuring Inflation: The Core is Rotten. Federal Reserve Bank of St. Louis Review 93(4), 223-233.

CBC News (2009) Inflation, Why Do Prices Rise and Fall? Your Money. July 17, 2009. Available at http://www.cbc.ca/consumer/story/2009/07/17/f-economy-inflation-deflation.html.

Coy, Peter (2008) The Great Inflation Debate. BusinessWeek. June 13, 2008. Available at http://www.businessweek.com/bwdaily/dnflash/content/jun2008/db20080613_966843.htm.

Kang, Kyu Ho, Chang-Jin Kim, and James C. Morley (2009) Changes in U.S. Inflation Persistence. Studies in Nonlinear Dynamics and Econometrics 13(4), 1-21.

Kiley, Michael T. (2008) Estimating the Common Trend Rate of Inflation for Consumer Prices and Consumer Prices Excluding Food and Energy Board of Governors of the Federal Reserve System Finance and Economics Discussion Series No. 2008-38, July 2008. Available at www.federalreserve.gov/pubs/feds/2008/200838/200838pap.pdf.

Kim, Chang-Jin, Pym Manopimoke, and Charles R. Nelson (2011) Trend Inflation and the New Keynesian Phillips Curve. Working paper.

Levin, T. Andrew, and Jeremy Piger (2003) Is Inflation Persistence Intrinsic in Industrial Economies?. Federal Reserve Bank of St. Louis Working Paper No. 2002-023.

Leybourne, Stephen, Tae-Hwan Kim, Vanessa Smith and Paul Newbold (2003) Test For A Change In Persistence Against The Null Of Difference-Stationarity. Econometric Journal 6, 291311.

McElroy, Tucker S. and Thomas M. Trimbur (2012) Signal Extraction for Multivariate Nonstationary Time Series. Finance and Economics Discussion Series Paper No. 2012-45. 
Mishkin, Frederic S. (2007) Headline versus Core Inflation in the Conduct of Monetary Policy. Speech delivered at the Business Cycles, International Transmission and Macroeconomic Policies Conference, Montreal, Canada, October 20. Available at http://www.drduru.com/money/SavedFiles/071020_FRB-Speech-Mishkin-Inflation.htm

Mitra, Sinchan and Tara M. Sinclair (2005). "Output Fluctuations in the G-7: An Unobserved Components Approach,” Macroeconomic Dynamics. volume 16, issue 03, pp. 396-422.

Morley, James C. (1999) A Note on Constraining AR(2) Parameters in Estimation. Manuscript.

Morley, James C. (2007) The Slow Adjustment of Aggregate Consumption to Permanent Income. Journal of Money, Credit, and Banking vol. 39, pp. 615-638.

Morley, James C., Charles R. Nelson, and Eric Zivot (2003) Why Are the Beveridge-Nelson and Unobserved-Components Decompositions of GDP So Different? The Review of Economics and Statistics 85(2), 235-243.

Morley, James C., Irina Panovska, and Tara M. Sinclair (2012) Testing Stationarity for an Unobserved Components Model. Working Paper. Available at:

http://papers.ssrn.com/sol3/papers.cfm?abstract_id=2162268

Morley, James C., Jeremy Piger and Robert Rasche (2011) Inflation in the G7: Mind the Gap(s)? St. Louis Federal Reserve Working Paper No. 2011-011.

Murray, Christian, Alex Nikolsko-Rzhevskyy, and David Papell (2008) Inflation Persistence and the Taylor Principle. Working paper.

Nelson, Charles R. and Charles R. Plosser (1982) Trends and Random Walks in Macroeconomic Time Series. Journal of Monetary Economics 10, 139-162.

Oh, Kum Hwa and Eric Zivot (2006). The Clark model with Correlated Components. Working Paper available at: http://papers.ssrn.com/sol3/papers.cfm?abstract_id=877398

Oh, Kum Hwa, Eric Zivot, Drew Creal (2008) The relationship between the Beveridge-Nelson decomposition and other permanent-transitory decompositions that are popular in economics, Journal of Econometrics, Volume 146, Issue 2, 207-219.

Picerno James (2005) In Core We Trust?. The Capital Spectator November 29, 2005. Available at: http://www.capitalspectator.com/archives/2005/11/in_core_we_trus.html

Piger, Jeremy and Robert Rasche (2008). Inflation: Do Expectations Trump the Gap? International Journal of Central Banking, 4, 85-116.

Pivetta, Frederic, and Ricardo Reis (2007) The Persistence of Inflation in the United States. Journal of Economic Dynamics and Control 31(4) (2007), 1326-1358. 
Roberts, John M. (1997). “Is Inflation Sticky?” Journal of Monetary Economics, Volume 39, Issue 2, Pages 173-196.

Sinclair, Tara M. (2009) The Relationships between Permanent and Transitory Movements in U.S. Output and the Unemployment Rate. Journal of Money, Credit and Banking 41(2-3), 529542.

Smith, Aaron. (2005), Forecasting in the presence of level shifts. Journal of Forecasting, 24: 557-574.

Stock, James H., and Mark W. Watson (2007) Why has US Inflation Become Harder to Forecast?. Journal of Money, Credit and Banking 39(1), 3-33. 